\title{
Towards tuberculosis elimination: an action framework for low-incidence countries
}

\author{
Knut Lönnroth ${ }^{1,60}$, Giovanni Battista Migliori ${ }^{2,60}$, Ibrahim Abubakar ${ }^{3}$, \\ Lia D’Ambrosio ${ }^{2}$, Gerard de Vries $^{4}$, Roland Diel ${ }^{5}$, Paul Douglas 6 , Dennis Falzon ${ }^{1}$, \\ Marc-Andre Gaudreau ${ }^{7}$, Delia Goletti ${ }^{8}$, Edilberto R. González Ochoa9, \\ Philip LoBue ${ }^{10}$, Alberto Matteelli ${ }^{1}$, Howard Njoo ${ }^{7}$, Ivan Solovic ${ }^{11}$, Alistair Story ${ }^{12}$, \\ Tamara Tayeb ${ }^{13}$, Marieke J. van der Werf ${ }^{14}$, Diana Weil ${ }^{1}$, Jean-Pierre Zellweger ${ }^{15}$, \\ Mohamed Abdel Aziz ${ }^{16}$, Mohamed R.M. Al Lawati ${ }^{17}$, Stefano Aliberti ${ }^{18}$, \\ Wouter Arrazola de Oñate ${ }^{19}$, Draurio Barreira ${ }^{20}$, Vineet Bhatia ${ }^{1}$, \\ Francesco Blasi ${ }^{21}$, Amy Bloom ${ }^{22}$, Judith Bruchfeld ${ }^{23}$, Francesco Castelli ${ }^{24}$, \\ Rosella Centis ${ }^{2}$, Daniel Chemtob ${ }^{25}$, Daniela M. Cirillo ${ }^{26}$, Alberto Colorado ${ }^{27}$, \\ Andrei Dadu ${ }^{28}$, Ulf R. Dahle ${ }^{29}$, Laura De Paoli ${ }^{30}$, Hannah M. Dias ${ }^{1}$, \\ Raquel Duarte ${ }^{31}$, Lanfranco Fattorini ${ }^{32}$, Mina Gaga ${ }^{33}$, Haileyesus Getahun ${ }^{1}$, \\ Philippe Glaziou ${ }^{1}$, Lasha Goguadze ${ }^{34}$, Mirtha del Granado ${ }^{35}$, Walter Haas ${ }^{36}$, \\ Asko Järvinen ${ }^{37,38}$, Geun-Yong Kwon ${ }^{39}$, Davide Mosca ${ }^{40}$, Payam Nahid ${ }^{41,42}$, \\ Nobuyuki Nishikiori ${ }^{43}$, Isabel Noguer ${ }^{44}$, Joan O'Donnell ${ }^{45}$, Analita Pace-Asciak ${ }^{46}$, \\ Maria G. Pompa ${ }^{47}$, Gilda G. Popescu ${ }^{48}$, Carlos Robalo Cordeiro ${ }^{49}$, \\ Karin Rønning ${ }^{29}$, Morten Ruhwald ${ }^{50}$, Jean-Paul Sculier ${ }^{51}$, Aleksandar Simunović ${ }^{52}$, \\ Alison Smith-Palmer ${ }^{53}$, Giovanni Sotgiu ${ }^{54}$, Giorgia Sulis ${ }^{1}$, 'Carlos A. Torres-Duque ${ }^{55}$ ', \\ Kazunori Umeki ${ }^{56}$, Mukund Uplekar $^{1}$, Catharina van Weezenbeek ${ }^{4}$, \\ Tuula Vasankari ${ }^{37}$, Robert J. Vitillo ${ }^{57}$, Constantia Voniatis ${ }^{58}$, Maryse Wanlin ${ }^{59}$ and \\ Mario C. Raviglione ${ }^{1}$
}

ABSTRACT This paper describes an action framework for countries with low tuberculosis (TB) incidence $(<100 \mathrm{~TB}$ cases per million population) that are striving for TB elimination. The framework sets out priority interventions required for these countries to progress first towards "pre-elimination" $(<10$ cases per million) and eventually the elimination of TB as a public health problem (less than one case per million). TB epidemiology in most low-incidence countries is characterised by a low rate of transmission in the general population, occasional outbreaks, a majority of TB cases generated from progression of latent TB infection (LTBI) rather than local transmission, concentration to certain vulnerable and hard-toreach risk groups, and challenges posed by cross-border migration. Common health system challenges are that political commitment, funding, clinical expertise and general awareness of TB diminishes as TB incidence falls. The framework presents a tailored response to these challenges, grouped into eight priority action areas: 1) ensure political commitment, funding and stewardship for planning and essential services; 2) address the most vulnerable and hard-to-reach groups; 3 ) address special needs of migrants and crossborder issues; 4) undertake screening for active TB and LTBI in TB contacts and selected high-risk groups, and provide appropriate treatment; 5) optimise the prevention and care of drug-resistant TB; 6) ensure continued surveillance, programme monitoring and evaluation and case-based data management; 7) invest in research and new tools; and 8) support global TB prevention, care and control. The overall approach needs to be multisectorial, focusing on equitable access to high-quality diagnosis and care, and on addressing the social determinants of TB. Because of increasing globalisation and population mobility, the response needs to have both national and global dimensions. 
Affiliations: ${ }^{1}$ Global TB Programme, World Health Organization, Geneva, Switzerland. ${ }^{2}$ WHO Collaborating Centre for Tuberculosis and Lung Diseases, Fondazione S. Maugeri, IRCCS, Tradate, Italy. ${ }^{3}$ TB Section, University College London and Public Health England, London, UK. ${ }^{4} \mathrm{KNCV}$ Tuberculosis Foundation, The Hague, The Netherlands. ${ }^{5}$ University Hospital Schleswig Holstein, Institute for Epidemiology, Kiel, Germany. ${ }^{6}$ Global Health Borders Refugee and Onshore Services, Dept of Immigration and Border Protection, Sydney, Australia. ${ }^{7}$ Centre for Communicable Diseases and Infection Control, Public Health Agency of Canada, Montreal, QC, Canada. ${ }^{8}$ National Institute for Infectious Diseases, Rome, Italy. ${ }^{9}$ Research and Surveillance Group on TB, Leprosy and ARI, Epidemiology Board, Institute of Tropical Medicine "Pedro Kouri", Havana, Cuba. ${ }^{10}$ Division of TB Elimination, Centers for Disease Control and Prevention, Atlanta, GA, USA. ${ }^{11}$ TB Dept, National Institute for TB, Respiratory Diseases and Thoracic Surgery, Vysne Hagy, Catholic University, Ružomberok, Slovakia. ${ }^{12}$ Find and Treat, London, UK. ${ }^{13}$ National TB Control Programme, Ministry of Health, Riyadh, Saudi Arabia. ${ }^{14}$ European Centre for Disease Prevention and Control (ECDC). Stockholm, Sweden. ${ }^{15}$ Swiss Lung Association, Bern, Switzerland. ${ }^{16}$ WHO Regional Office for the Eastern Mediterranean, Cairo, Egypt. ${ }^{17}$ Ministry of Health, Muscat, Oman. ${ }^{18}$ Università degli Studi di Milano - Bicocca, UO Clinica Pneumologica, AO San Gerardo, Monza, Italy. ${ }^{19}$ Belgian Lung and Tuberculosis Association, Brussels, Belgium. ${ }^{20}$ Ministry of Health, Brasilia, Brazil. ${ }^{21}$ Dipartimento Fisiopatologia Medico-Chirurgica e dei Trapianti, University of Milan, IRCCS Fondazione Cà Granda, Milan, Italy. ${ }^{22}$ US Agency for International Development, Washington, DC, USA. ${ }^{23}$ Unit of Infectious Diseases, Institution of Medicine, Karolinska Institute Solna and Karolinska University Hospital, Stockholm, Sweden. ${ }^{24}$ University of Brescia, Brescia, Italy. ${ }^{25}$ Ministry of Health, Jerusalem, Israel. ${ }^{26}$ IRCCS San Raffaele Scientific Institute, Milan, Italy. ${ }^{27}$ Advocates for Health International, San Diego, CA, USA. ${ }^{28}$ TB and M/XDR-TB Control Programme, WHO Regional Office for Europe, Copenhagen, Denmark. ${ }^{29}$ Norwegian Institute of Public Health, Oslo, Norway. ${ }^{30}$ Médecins sans Frontières, Rome, Italy. ${ }^{31}$ General Directorate of Health, Lisbon, Portugal. ${ }^{32}$ Istituto Superiore di Sanita, Rome, Italy. ${ }^{33}$ National Referral Centre for Mycobacteria, Athens Chest Hospital, Ministry of Health, Athens, Greece. ${ }^{34}$ International Federation of Red Cross and Red Crescent Societies, Geneva, Switzerland. ${ }^{35}$ WHO Regional Office for the Americas, Washington, DC, USA. ${ }^{36}$ Dept of Infectious Disease Epidemiology, Robert Koch Institute, Berlin, Germany. ${ }^{37}$ Finnish Lung Health Association, Helsinki, Finland. ${ }^{38}$ Helsinki University Central Hospital, Division of Infectious Diseases, Helsinki, Finland. ${ }^{39}$ Korea Centers for Disease Control and Prevention (KCDC), Ministry of Health and Welfare, Seoul, Republic of Korea. ${ }^{40}$ International Organization for Migration, Geneva, Switzerland. ${ }^{41}$ University of California, San Francisco, CA, USA. ${ }^{42}$ American Thoracic Society (ATS), New York, NY, USA. ${ }^{43}$ Stop TB and Leprosy Elimination, WHO Regional Office for the Western Pacific, Manila, Philippines. ${ }^{4}$ Instituto de Salud Carlos III, Madrid, Spain. ${ }^{45} \mathrm{HSE}$ Health Protection Surveillance Centre, Dublin, Ireland. ${ }^{46} \mathrm{Ministry}$ for Health, Valletta, Malta. ${ }^{47}$ Ministry of Health, Rome, Italy. ${ }^{48}$ Pneumology Institute Marius Nasta, Bucharest, Romania. ${ }^{49}$ Coimbra University Hospital, Coimbra, Portugal. ${ }^{50}$ Statens Serum Institut (SSI), Copenhagen, Denmark. ${ }^{51}$ Institut Jules Bordet (ULB), Brussels, Belgium. ${ }^{52}$ Croatian National Institute of Public Health, Zagreb, Croatia. ${ }^{53}$ Health Protection Scotland, Glasgow, UK. ${ }^{54}$ Clinical Epidemiology and Medical Statistics Unit, Dept of Biomedical Sciences, University of Sassari, Research, Medical Education and Professional Development Unit, AOU Sassari, Sassari, Italy. ${ }^{55}$ Asociacion Latinoamericana de Torax (ALAT) - Fundacion Neumologica Colombiana, Bogota, Colombia. ${ }^{56}$ Ministry of Health, Labour and Welfare, Tokyo, Japan. ${ }^{57}$ Caritas Internationalis, Geneva, Switzerland. ${ }^{58}$ Ministry of Health, Nicosia, Cyprus. ${ }^{59}$ Fonds des Affections Respiratoires (FARES), Brussels, Belgium. ${ }^{60}$ Both authors contributed equally.

Correspondence: Mario C. Raviglione, Global TB Programme, World Health Organization, 20 avenue Appia, $\mathrm{CH}-1211$, Geneva 27, Switzerland. E-mail: raviglionemawho.int

Received: Nov 202014 | Accepted after revision: Jan 022015

Support statement: This work was supported by core funding from the European Respiratory Society.

Conflict of interest: Disclosures can be found alongside the online version of this article at erj.ersjournals.com

The content of this work is @ the authors or their employers. Design and branding are @ERS 2015. ERJ Open articles are open access and distributed under the terms of the Creative Commons Attribution Non-Commercial Licence 4.0. This article is one of a small annual allocation selected for open access publication at the discretion of the editor. 


\section{Introduction}

Tuberculosis (TB) remains a major public health problem predominantly affecting low- and middle-income countries. It kills 1.5 million people every year [1]. It is a persistent health threat in high-income countries too, especially among immigrants and the poorest and most vulnerable parts of the population [2-7].

With a vision to progress towards finally eliminating this ancient scourge, the World Health Organization (WHO) has developed a global TB strategy with a perspective beyond 2015 [8]. Its vision, goal, targets and main intervention elements are summarised in table 1 . The global strategy includes milestones towards a long-term vision to eliminate $\mathrm{TB}$ as a public health problem (defined as less than one case of TB per million population). It includes a goal to reduce global TB incidence from $>1000$ cases per million population today to $<100$ cases per million by 2035 [9].

The global strategy emphasises the need for country adaptation and prioritisation according to the local epidemiology and the healthcare systems. With the anticipated global progress, a growing number of countries will in the future enter into the low-incidence category, that is, countries that reach $<100 \mathrm{~TB}$ cases (all forms) per million population. These countries will need to progress further towards pre-elimination $(<10$ cases per million) and eventually elimination. This will require additional actions to improve access to high-quality TB services especially for vulnerable groups, as well as efforts to address the underlying determinants that put people at risk of TB. In a globalised world, TB will not be sustainably eliminated in any country until it is eliminated globally. This interdependency calls for joint and intensified efforts on TB prevention, care and control in all countries (fig. 1).

This paper presents the first global framework towards TB elimination in low-incidence countries. It draws upon and consolidates previous national and regional frameworks [3, 10-15], while incorporating new tools and approaches [16] and harmonising with the structure and principles of the new global strategy [8].

We first summarise the epidemiological basis for TB elimination in low-incidence countries. We then review the key challenges and identify eight priority action areas. Finally, we discuss mechanisms for partner involvement and international collaboration. The methods are summarised in table 2.

\section{TABLE 1 The World Health Organization post-2015 global tuberculosis (TB) strategy [8]}

\section{Vision}

A world free of TB: zero deaths, disease and suffering due to TB

Goal

End the global TB epidemic

\section{Targets for 2035}

$95 \%$ reduction in TB deaths (compared with 2015)

$90 \%$ reduction in TB incidence rate ( $<10$ TB cases per 100000 population)

No affected families facing catastrophic costs due to TB

\section{Principles}

1) Government stewardship and accountability, with monitoring and evaluation

2) Strong coalition with civil society organisations and communities

3) Protection and promotion of human rights, ethics and equity

4) Adaptation of the strategy and targets at country level, with global collaboration

\section{Pillars and components}

1) Integrated, patient-centred care and prevention

A. Early diagnosis of TB including universal drug susceptibility testing, and systematic screening of contacts and high-risk groups

B. Treatment of all people with TB including drug-resistant TB, and patient support

C. Collaborative TB/HIV activities and management of comorbidities

D. Preventive treatment of persons at high-risk and vaccination against TB

2) Bold policies and supportive systems

A. Political commitment with adequate resources for TB care and prevention

B. Engagement of communities, civil society organisations and public and private care providers

C. Universal health coverage policy and regulatory frameworks for case notification, vital registration, quality and rational use of medicines, and infection control

D. Social protection, poverty alleviation and actions on other determinants of TB

3) Intensified research and innovation

A. Discovery, development and rapid uptake of new tools, interventions and strategies

B. Research to optimise implementation and impact, and promote innovations 


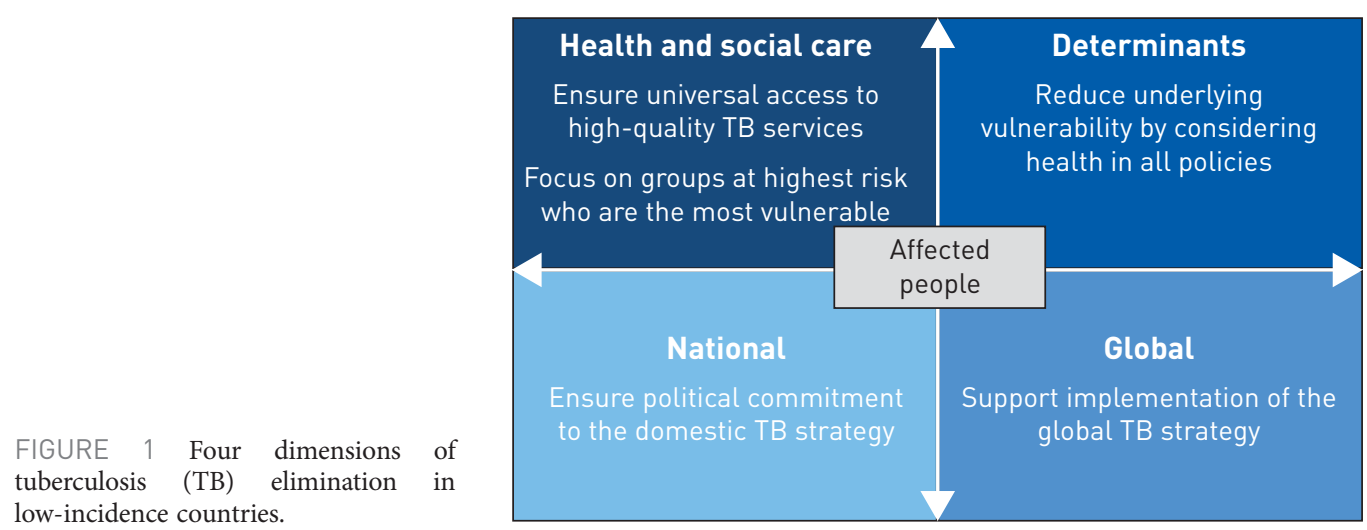

TABLE 2 Methods and definitions

\section{Methods}

The basis for this framework is the post-2015 global TB strategy, which was approved by the World Health Assembly in May 2014 [8]. The framework [17] is grounded in existing WHO guidelines related to TB care, prevention and control [18]. A narrative review of WHO policy documents and guidelines, as well as published literature, was undertaken. A writing group was established, which developed a draft in a framework-drafting meeting in Geneva in April 2014. It was then circulated to 32 country representatives and 22 additional representatives of research institutions and technical agencies, nongovernmental and civil society organisations that were invited to a global consultation meeting in Rome, on July 4-5, 2014 [19].

\section{Data sources}

Data on TB epidemiology and health systems context described in the framework draw on four data sources: 1) the WHO global TB database [20], 2) a published survey of TB policies in the European Union countries [14], 3) other published research, and 4) a survey conducted among all countries invited to the Global Consultation. The latter survey included questions concerning elements of TB epidemiology that are not routinely reported to the WHO but are available in national surveillance datasets (to various extent), as well as questions about existing policy and practice with regard to specific TB care and control interventions.

\section{Low-incidence countries}

In this framework, low-incidence countries are defined as those with a TB notification rate of $<100$ notified TB cases (all forms) per million population. This definition has been previously proposed [10], while others have suggested alternative thresholds, such as $<200$ per million [3] or $<160$ per million [21]. The $<100$ per million threshold is the same as the global incidence rate target for 2035 , which corresponds to the goal of the post-2015 global TB strategy to "end the global TB epidemic" (table 1). However, this framework is not only relevant for countries that meet this particular low-incidence criterion. The principles and proposed actions are similar for other countries that are approaching the low-incidence threshold.

\section{Pre-elimination and elimination}

Pre-elimination is defined as $<10$ notified TB cases (all forms) per million population and year. This is the same as proposed by CLANCY et al. [10] in 1991. Elimination of TB as a public health problem is defined as less than one notified TB case (all forms) per million population and year. For the European region, TB elimination was previously defined as less than one sputum-smear-positive case per million, and thus focused on the most infectious TB cases only [22]. However, the European Centre for Disease Prevention and Control has proposed a definition that includes all forms of TB [11]. Similarly, the US Centres for Disease Control and Prevention defines elimination in the USA as less than one case of TB, all forms, per million population [11, 12].

\section{Notification rate versus true incidence rate}

These definitions use TB notification rate rather than estimated incidence, given that health systems as well as TB surveillance systems are of generally high quality in low-incidence countries and therefore the gap between notification rate of new and relapse cases and true incidence rate is small [1]. Nevertheless, TB notification rates should always be evaluated in the context of the coverage of TB surveillance systems, specifically the likelihood of significant under-detection and/or under-reporting of TB. WHO guidance is available for this purpose $[23,24]$.

TB: tuberculosis; WHO: World Health Organization. 


\section{Epidemiological trends and prospects for reaching elimination in low-incidence countries}

Excluding a few very small countries and territories, no country has yet reached the TB elimination threshold. Table 3 summarises the TB burden, recent trends and future projections for 33 countries and territories with TB notification rate of $<100$ per million in 2012 (excluding countries and territories with a population of $<300000$ people: Anguilla, Antigua and Barbuda, Bonaire, Saint Eustatius and Saba, Bermuda, Barbados, Cook Islands, Curacao, Dominica, Grenada, Saint Kitts and Nevis, Saint Lucia, Montserrat, Niue, Sint Maarten (Dutch part), and British Virgin Islands).

All but six of these countries have experienced a downward trend between 2000 and 2012. The unweighted average rate of decline for the 33 countries was $3 \%$ per year. With the current rate of decline, only four countries would reach pre-elimination by 2035, none would reach TB elimination by 2035, and only one would reach elimination by 2050 . In order to reach TB elimination by 2035 , the required average annual rate of decline from 2015 onwards would range from $12 \%$ to $20 \%$ across countries, with a mean of $18 \%$, i.e. a much faster decline than that experienced by most of these countries in the recent past (table 3 and fig. 2). The average annual rate of decline required to reach elimination in 2050 would range between $7 \%$ and $13 \%$ (fig. 3 ).

The task of reaching TB elimination in the coming decades may thus seem daunting, even in countries with the lowest incidence in the world. However, TB rates are already at pre-elimination levels and are getting closer to the elimination levels for the non-foreign-born population in some high-income countries (fig. 4) [25]. Very low TB rates have been achieved in settings that have secured a combination of near-universal access to high-quality $\mathrm{TB}$ diagnosis and treatment, social protection and general socioeconomic development with improved nutrition and living and working conditions [4, 26-28]. From these observations we can deduce that TB elimination is possible with current tools, provided that the above factors would continue to improve and apply for all people. However, reaching elimination would take many decades even with full scale-up of current technologies and improved socioeconomic conditions. Moreover, the prospect of such progress in low-incidence countries hinges on the effectiveness of measures taken to treat, control and prevent TB elsewhere in the world [29].

If the global TB strategy target of 90\% reduction in TB incidence between 2015 and 2035 (table 1) [8] could be reached in all low-incidence countries, it would bring all but two of them to pre-elimination levels, but none of them to elimination by 2035 (fig. 5). It should be noted that an underlying assumption for the $90 \%$ reduction target is that new tools for prevention, diagnosis and treatment would become available around 2025 at the latest, allowing a further acceleration of decline in the following decade [30]. Therefore, even if technological advances are realised, it seems reasonable for most low-incidence countries to have pre-elimination as a goal for 2035 , while a later target date is needed for the elimination goal.

The above projections are based on an optimistic assumption that the trends will continue in a favourable direction and then accelerate. While aspiring to this, it is critical to consider and mitigate the threats that can lead to a deceleration or even reversed trends, such as the dismantling of TB control programmes [31, 32], further spreading of HIV [5], an increase in drug-resistant TB [33], increases of some noncommunicable diseases that are risk factors for TB [34, 35], an increase in migration [36], economic crises [37] and growing inequity [4]. Income inequality remains an important predictor of TB burden in low-incidence countries today and insufficient social protection presents an obstacle for further progress $[28,38]$.

\section{Adapting the global strategy to the special challenges for TB care and prevention in low-incidence countries: eight priority action areas}

Prioritisation of key interventions and target groups should be based on an epidemiological and health system assessment in each setting, guided by data analysis and operational research. Critically, such analyses need to establish the distribution of TB in the population (by age, sex, geographical location and sociodemographic variables), the specific access barriers that each risk group faces, the health system capacity and bottlenecks, and the availability and quality of TB-specific interventions and programmatic functions.

TB epidemiology in most low-incidence countries is characterised by a low rate of transmission in the general population, occasional outbreaks, a majority of TB cases generated from progression of latent TB infection (LTBI) rather than recent transmission, a high degree of concentration in certain vulnerable and hard-to-reach risk groups, a significant contribution to TB rates from cross-border migration, and changes in age distribution towards the highest number of cases among the elderly, at least in the non-foreign-born population [3, 14, 36, 39-42]. However, the importance and nature of these elements vary across countries, and a detailed situation analysis is needed in each setting. 
TABLE 3 Tuberculosis (TB) burden trends and projections in 33 low-incidence countries

\begin{tabular}{|c|c|c|c|c|c|c|c|c|c|}
\hline Country or territory & $\begin{array}{l}\text { Population } \\
\text { millions }\end{array}$ & $\begin{array}{l}\text { Estimated TB } \\
\text { mortality } \\
\text { rate in } 2012 \\
\text { per million }\end{array}$ & $\begin{array}{l}\text { Estimated TB } \\
\text { incidence } \\
\text { rate in } 2012 \\
\text { per million }\end{array}$ & $\begin{array}{l}\text { TB notification } \\
\text { rate in } 2012 \\
\text { per million }\end{array}$ & $\begin{array}{c}\text { Foreign-born } \\
\text { notified TB } \\
\text { cases in } \\
2012^{\text {II }} \%\end{array}$ & $\begin{array}{l}\text { Annual rate } \\
\text { of change in } \\
\text { incidence in } \\
2000-2012^{+} \%\end{array}$ & $\begin{array}{l}\text { Incidence per } \\
\text { million in } \\
2035 \text { if } 90 \% \\
\text { reduction in } \\
2015-2035\end{array}$ & $\begin{array}{c}\text { Required } \\
\text { annual rate of } \\
\text { decline to reach } \\
\text { elimination by } \\
2035 \%\end{array}$ & $\begin{array}{c}\text { Required } \\
\text { annual rate of } \\
\text { decline to reach } \\
\text { elimination by } \\
2050 \%\end{array}$ \\
\hline Australia & 23.1 & 1.9 & 64 & 57 & 87 & 0.8 & 6.5 & -18 & -11 \\
\hline Austria & 8.5 & 4.2 & 79 & 73 & 49 & -6.1 & 6.6 & -19 & -12 \\
\hline Bahamas & 0.4 & 3.7 & 110 & 86 & 0 & -6.9 & 9.0 & -20 & -12 \\
\hline Belgium & 11.1 & 5.9 & 93 & 82 & 53 & -3.3 & 8.4 & -20 & -12 \\
\hline Canada & 34.8 & 1.9 & 50 & 48 & 64 & -2.2 & 4.7 & -17 & -10 \\
\hline Costa Rica & 4.6 & 8.0 & 119 & 99 & 15 & -4.1 & 10.5 & -21 & -13 \\
\hline Cuba & 11.3 & 3.3 & 93 & 65 & 2 & -2.1 & 8.7 & -20 & -12 \\
\hline Cyprus & 1.1 & 2.0 & 64 & 79 & 74 & 4.8 & 7.4 & -18 & -11 \\
\hline Czech Republic & 10.7 & 3.5 & 59 & 56 & 17 & -8.6 & 4.6 & -18 & -11 \\
\hline Denmark & 5.6 & 4.0 & 70 & 61 & 61 & -3.8 & 6.3 & -18 & -11 \\
\hline Finland & 5.4 & 2.9 & 62 & 48 & 29 & -4.7 & 5.4 & -18 & -11 \\
\hline France & 63.9 & 4.6 & 89 & 74 & 56 & -2.7 & 8.2 & -20 & -12 \\
\hline Germany & 82.8 & 3.5 & 53 & 49 & 48 & -6.6 & 4.4 & -17 & -10 \\
\hline Greece & 11.1 & 6.9 & 48 & 47 & 38 & -3.9 & 4.3 & -17 & -10 \\
\hline Iceland & 0.3 & 2.7 & 40 & 31 & 82 & -0.3 & 4.0 & -16 & -10 \\
\hline Ireland & 4.6 & 3.9 & 83 & 75 & 44 & -3.1 & 7.5 & -19 & -12 \\
\hline Israel & 7.6 & 2.3 & 58 & 62 & 90 & -4.6 & 5.0 & -18 & -11 \\
\hline Italy & 60.9 & 4.3 & 62 & 51 & 58 & -2.5 & 5.7 & -18 & -11 \\
\hline Jamaica & 2.8 & 2.2 & 65 & 33 & NA & 0.0 & 6.5 & -18 & -11 \\
\hline Jordan & 7.0 & 5.3 & 58 & 47 & 29 & -2.5 & 5.4 & -18 & -11 \\
\hline Luxembourg & 0.5 & 4.2 & 73 & 86 & 71 & -3.5 & 6.5 & -20 & -12 \\
\hline Malta & 0.4 & 3.7 & 101 & 98 & 85 & 7.6 & 12.6 & -19 & -11 \\
\hline The Netherlands & 16.7 & 1.7 & 63 & 55 & 73 & -3.8 & 5.6 & -18 & -11 \\
\hline New Zealand & 4.5 & 1.0 & 74 & 66 & 76 & -3.8 & 6.6 & -19 & -11 \\
\hline Norway & 5.0 & 1.4 & 76 & 69 & 85 & 1.3 & 7.9 & -19 & -11 \\
\hline Puerto Rico & 3.7 & 2.3 & 22 & 19 & 13 & -7.9 & 1.7 & -13 & -8 \\
\hline Slovakia & 5.5 & 6.3 & 77 & 59 & 1 & -9.1 & 5.8 & -19 & -11 \\
\hline Slovenia & 2.1 & 9.7 & 84 & 65 & 35 & -8.1 & 6.6 & -19 & -12 \\
\hline Sweden & 9.5 & 1.4 & 68 & 62 & 85 & 2.5 & 7.4 & -18 & -11 \\
\hline Switzerland & 8.0 & 2.2 & 67 & 52 & 75 & -3.2 & 6.1 & -18 & -11 \\
\hline United Arab Emirates & 9.2 & 1.0 & 17 & 9 & NA & -11.9 & 1.2 & -12 & -7 \\
\hline USA & 318.0 & 1.4 & 36 & 32 & 63 & -5.0 & 3.1 & -16 & -9 \\
\hline West Bank and Gaza Strip & 4.2 & 2.3 & 76 & 8 & NA & -4.8 & 6.6 & -19 & -11 \\
\hline Unweighted average & & 4.02 & 68 & 66 & 54 & -3 & 6.3 & -18 & -11 \\
\hline
\end{tabular}

NA: not available. ": from the World Health Organization (WHO) global TB database [20]; ": from the WHO global TB database [20], updated with data from countries responding to the survey; ${ }^{+}$: annual rates of change, where estimated, were based on estimated incidence rates from the slope of a linear regression model using log-transformed rates. 


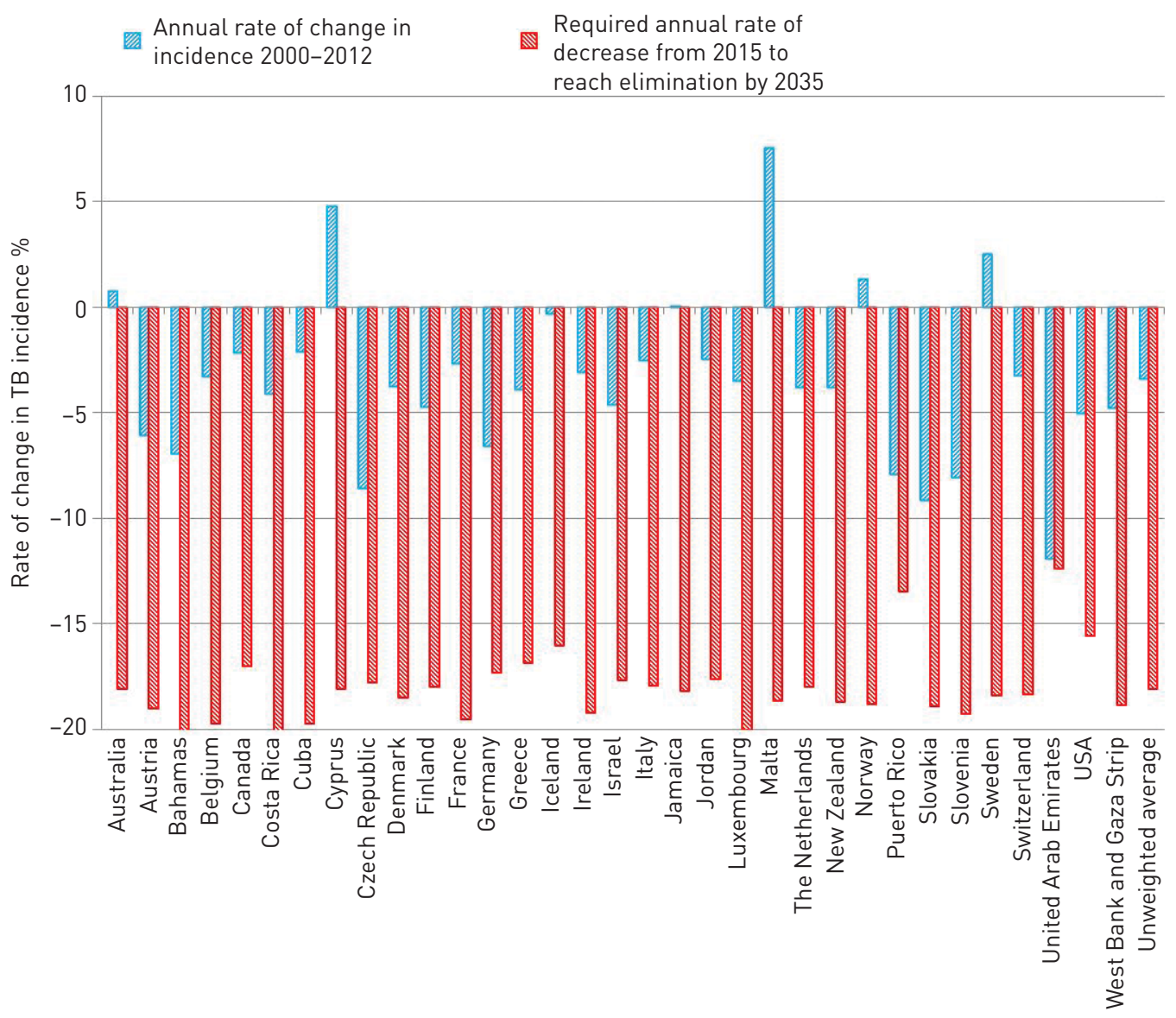

FIGURE 2 Observed versus required annual rate of change in tuberculosis (TB) incidence to reach TB elimination (less than one case per million) by 2035 in 33 low-incidence countries.

A common health system challenge for low-incidence countries is that the low burden of TB often leads to low visibility, which may translate into inadequate political commitment, insufficient public health response, limited clinical capacity and diminishing public awareness.

The special challenges require tailored responses, which in this framework are grouped under eight broad priority action areas. The specific challenges and corresponding priority actions for each are outlined below. Table 4 maps each action area against the components of the global TB strategy. The implementation of these actions should adhere to the same fundamental principles defined for the global strategy (table 5).

\section{1) Ensure political commitment, funding and stewardship for planning and essential services}

Most low-incidence countries have a relatively well-financed health system, and TB diagnosis and treatment are nominally free of charge (table 6). Despite these favourable basic conditions, several challenges exist. Critical health system challenges include ensuring that vulnerable populations are included under universal health coverage schemes that translate into access to needed health services for all people without financial hardship in using them [43]. Some low-incidence countries do not provide free TB care to all (table 6). Marginalised groups, such as homeless people and undocumented migrants, may be excluded from national health services or insurance schemes [14, 36, 44-46]. Moreover, co-payments, even if relatively small, can constitute financial barriers for some. Even where access is universal on paper, other important barriers can impede access and adherence, which include those linked to marginalisation, language, stigma and discrimination $[6,47]$.

These access barriers require a bold health system response. However, it is often difficult to maintain political commitment for TB care, prevention and control when TB incidence has declined to low levels. This may be reflected in the fact that fewer than half of the low-incidence countries have a national TB programme, a central unit responsible for national TB care and prevention, or TB-specific funding, while $60 \%$ have a TB elimination plan (table 6). 


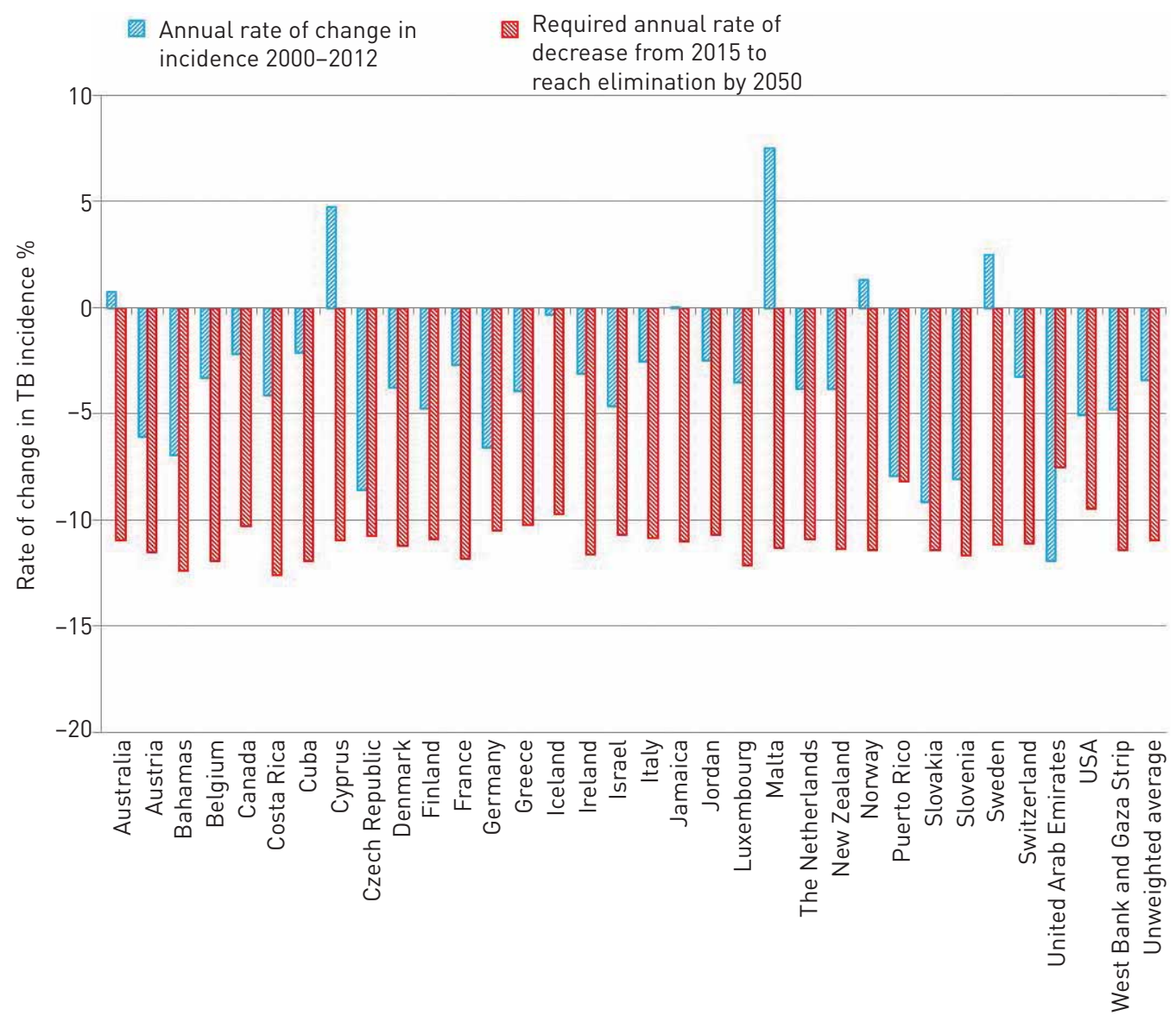

FIGURE 3 Observed versus required annual rate of change in tuberculosis (TB) incidence to reach TB elimination (less than one case per million) by 2050 in 33 low-incidence countries.

Several low-incidence countries have experienced de-prioritisation of TB control. Dropping crucial elements, such as surveillance, forecasting, strategic planning, guideline development, quality control, inclusion of TB in medical curricula and resource mobilisation, can have deleterious effects on TB care and prevention [48]. Under-funded or dismantled TB control units have led to lost attention to TB control and a surge in $\mathrm{TB}$ rates requiring massive re-investments to curb these trends $[31,32]$. In recent years, stock-outs of TB medicines or diagnostics [49], loss of clinical expertise and diminishing proficiency for TB testing in laboratories have been reported and linked to weakened TB surveillance and planning [50, 51].

For surveillance, it is essential to have a mandatory notification policy embedded in public health laws that fully respect human rights and ethical principles. TB notification is mandatory in all low-incidence countries, although significant under-reporting has been described for some settings [52-54]. Most low-incidence countries have individual case-based electronic TB surveillance (table 6). However, only 61\% of European countries perform regular supervision and only $39 \%$ have a monitoring and evaluation plan [14].

\section{Key interventions}

Central coordination under government stewardship, which can be enhanced through establishment of a national TB policy committee, should ensure the development of a national strategic plan for TB elimination embedded in national health and social sector plans, and accountability for its implementation. The central coordination should ensure that a cohesive and dedicated TB public health infrastructure is in place, which is vigilant in addressing all aspects of TB care and prevention, and ensure adequate surveillance and monitoring. The required size and capacity for a central coordination team, the need for specialised units for TB diagnosis and treatment, and the appropriate level of centralisation or de-centralisation of services depends on the size of the country as well as TB burden and distribution. The following functions must be fulfilled: 1) formulation of standards and protocols and incorporation of these in the national legal and regulatory framework for health; 2) well-functioning chains of care, with strong referral, notification and information mechanisms between primary care, hospitals and specialised services, both public and private $[48,55]$; 3) human resource planning, capacity strengthening, basic and 


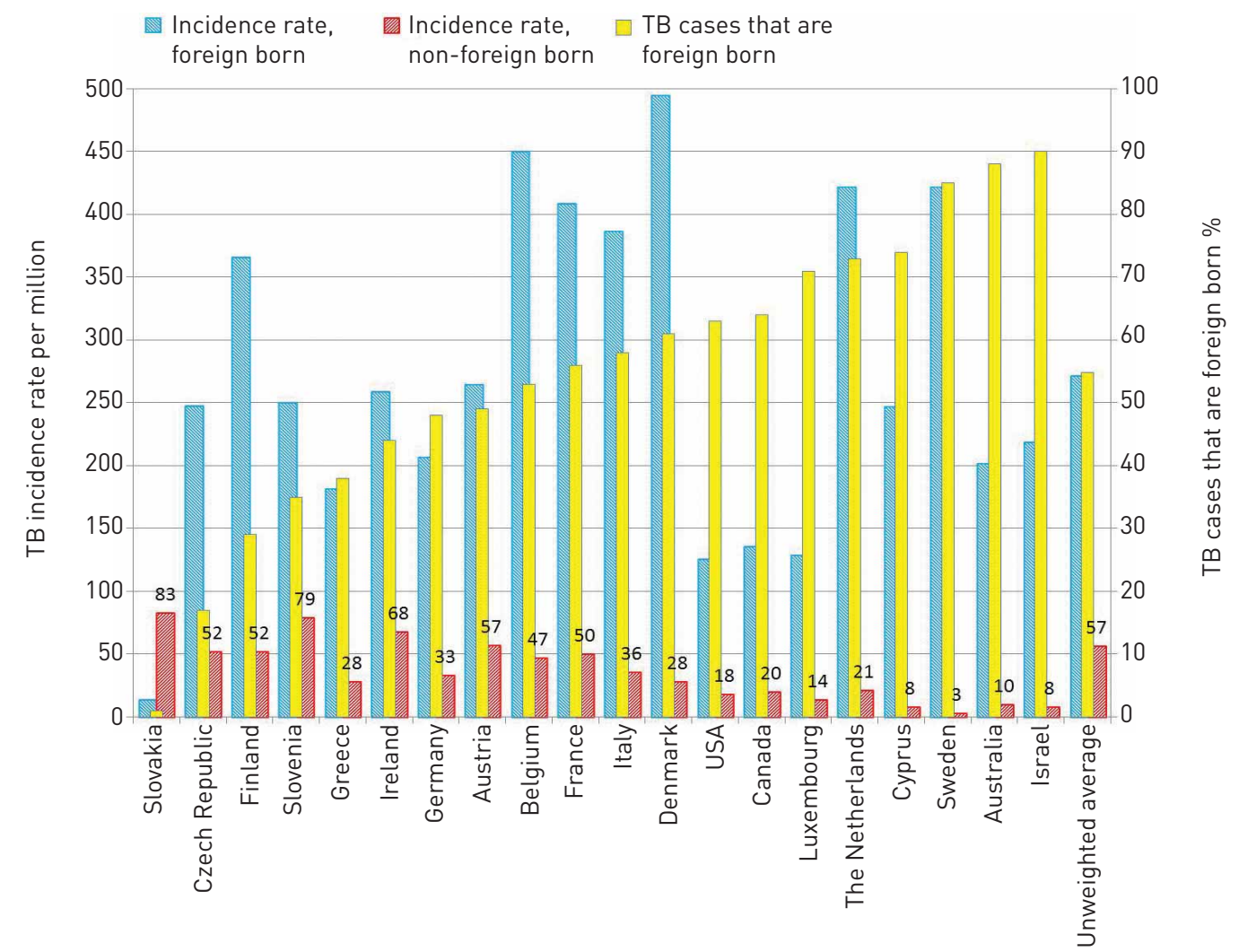

FIGURE 4 Tuberculosis (TB) incidence rate in foreign-born and non-foreign-born populations, and proportion of TB cases that are foreign born in selected low-incidence countries, from 2012 data. The inserted numbers are the incidence rates per million in non-foreign-born populations.

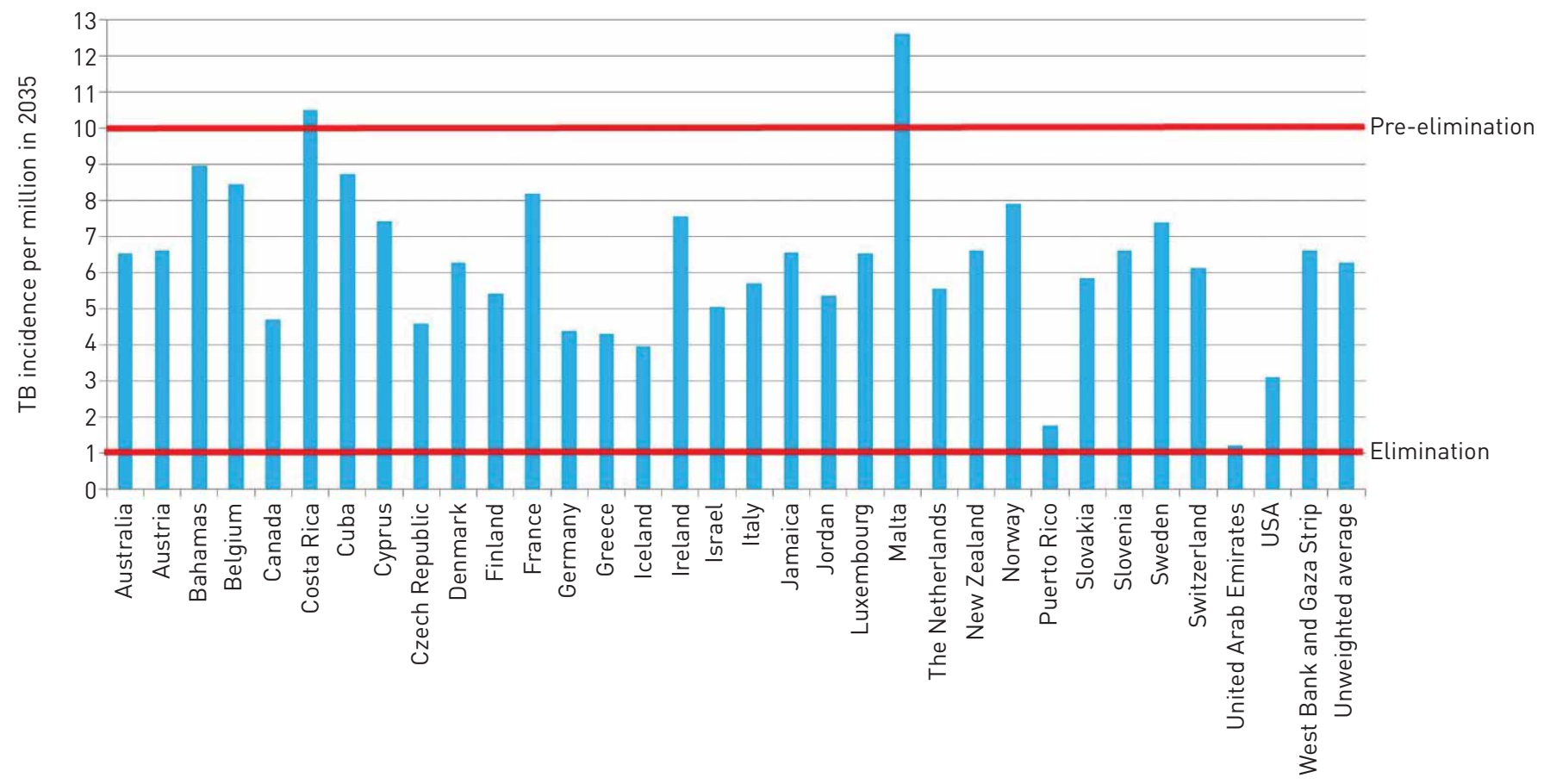

FIGURE 5 Projected tuberculosis (TB) incidence rates in 33 low-incidence countries in 2035 assuming a decline of $90 \%$ between 2015 and 2035 . The defined pre-elimination and elimination levels are shown. 
TABLE 4 Adaptation of the post-2015 global tuberculosis (TB) strategy to low-incidence countries

Priority action area

Key interventions
Global strategy

pillars and

components
1 Ensure political commitment, funding and stewardship for planning and essential services of high quality

2 Address the most vulnerable and hard-to-reach groups

3 Address special needs of migrants and cross-border issues

4 Undertake screening for active TB and LTBI in TB contacts and selected high-risk groups, and provide appropriate treatment

5 Optimise the prevention and care of drug-resistant TB

6 Ensure continued surveillance, programme monitoring and evaluation and case-based data management

7 Invest in research and new tools

8 Support global TB prevention, care and control
Political commitment and financing (plans, targets and leadership) 1A-D

Advocacy from civil society, communities and other stakeholders 2A-D

Central coordination, management and staffing for

TB elimination, including training, laboratory capacity,

TB test and drug forecasting and management, and surveillance

Partnerships among ministries, sectors and stakeholders

Mapping of TB risk groups, including all groups with elevated 1A-D

TB incidence and hard-to-reach groups

2B-D

Analysing and addressing barriers to access and adherence

Social support and protection

Addressing underlying social determinants

Undertaking epidemiological assessment and proper surveillance 1A-D

Ensuring access to culturally sensitive health services 2B-D

Social support

Establishment of cross-border collaboration

Considering selective screening (pre- and/or post-entry)

Addressing social determinants

Contact investigation

Outbreak management

Consideration and prioritisation of other screening activities on the basis of mapping of risk groups and assessing benefits, risks and costs

Monitoring for effectiveness of screening programmes and policies

Universal rapid drug susceptibility testing 1A-D

Optimised treatment, care, support and social protection 2A-D

Drug regulation and management $3 \mathrm{~A}-\mathrm{B}$

Enforcing compulsory notification $\quad 2 \mathrm{~A}-\mathrm{C}$

Establishing an electronic case-based TB registry

Implementing a core set of indicators for surveillance and monitoring of evaluation

Use of molecular epidemiology tools when needed

Linkage and integration with other surveillance systems

A monitoring and evaluation framework

Regular monitoring of implementation, with periodic evaluation and impact assessment

Mobilisation of financial resources for TB research

Influencing the research agenda of main institutions

Support for national and international capacity building for research

Contribution and mobilisation of financial resources

Promotion of global TB advocacy and visibility

Contributions to global TB surveillance, monitoring and evaluation

Support for bilateral and multilateral collaboration and technical assistance

LTBI: latent TB infection.

continuous medical education that include the development of TB consultant networks, and targeted educational campaigns [56]; 4) a high-quality network of laboratory services, validated through proficiency testing and other quality control mechanisms [57]; 5) an uninterrupted, quality-controlled supply of drugs and diagnostics, based on forecasting; drug management capabilities, and a strategy for rational drug use 
TABLE 5 Adaptation of the principles of the post-2015 global tuberculosis (TB) strategy to low-incidence settings

\section{1) Government stewardship and accountability, with monitoring and evaluation}

In low-incidence settings, government must undertake distinct actions in pursuing its stewardship function. These actions are not just those of public health authorities but necessitate clear roles and accountability of multiple authorities, including associated reinforcement and adaptation of monitoring and evaluation approaches, including cross-border collaboration.

\section{2) Strong coalition with civil society organisations and communities}

Reaching vulnerable and marginalised populations requires novel approaches to building coalitions with civil society organisations and communities most affected. This coalition approach can both increase expression of the demand for TB prevention and care and ensures engagement in the formulation of plans and intervention strategies, and their evaluation.

\section{3) Protection and promotion of human rights, ethics and equity}

Many of the individuals and groups most at risk of TB exposure, infection, disease and poor outcomes face challenges in the protection and promotion of their human rights in general, and in their right to health specifically. A human-rights-based approach to pursuing TB elimination is necessary. This includes addressing issues of nondiscrimination, availability, accessibility, acceptability and quality of interventions, privacy and confidentiality, participation and accountability. There are a range of related ethical issues that arise in the design and implementation of TB prevention and care interventions. Underlying inequities also need to be addressed in the TB response within and beyond the health sector, such as inequity in economic and social circumstances and related social determinants of disease, and in access to healthcare. There is also a need to address concerns that access to formal health services may disclose the irregular status of some immigrants and have legal implications.

\section{4) Adaptation of the strategy and targets at country level, with global collaboration}

The development of this framework itself is an expression of the principle of adaptation of global strategy to country and local context. Global collaboration is a fundamental element of the framework, because many of the challenges, including migration, building political commitment to TB elimination and ensuring a robust research portfolio, necessitate global collaboration.

(including fixed-dose combinations); and 6) high-quality collection and analysis of data and capacity of all levels of the health system in surveillance and programmatic monitoring and evaluation [58].

Public health authorities should ensure that high-quality TB care and associated social protection are available for all patients regardless of ability to pay for services. There should be capacity to use the best TB tests available for all in need and to provide optimal and comprehensive treatment for all people with TB and related comorbidities. (For detailed recommendations on TB prevention, diagnosis, treatment and care, see the full framework document [17], the global TB strategy [8] and related guidelines that are continually updated on the WHO website [18].)

Political commitment is also required for essential regulatory approaches, including an infectious disease law that is effectively implemented and enforced. Specific regulations are required for vital registration, mandatory TB case notification, screening of selected risk groups, access to care for undocumented immigrants, cross-border collaboration, treatment outcome monitoring, registration, importation, and manufacturing, prescribing and dispensing of TB tests and medicines, and infection control in healthcare services and other settings.

Baseline assessments of TB epidemiology and health system capacity are needed, and operational and impact target setting should be based on this knowledge. Regular reporting and public dissemination of results and lessons learned need to be stimulated and financed. Establishment of an advisory body that annually reviews routine performance of national efforts and progress towards targets should be considered. It should include relevant authorities, professional societies, researchers and civil society. In some countries, this may be best done through overarching communicable disease bodies.

Active involvement of civil society organisations, affected vulnerable communities or patient organisations can help pursue independent efforts complementary to those of the government. The partnership effort also needs to extend into the routine practice of local health and social services, public health practitioners, researchers and the private sector. The involvement of prison health services, occupational health departments, immigration authorities and special health and social services for vulnerable groups needs to be considered. $\mathrm{TB}$ control in large cities may require special initiatives planned together with city health authorities. 
TABLE 6 Health system context and tuberculosis (TB) service delivery in 22 low-incidence countries that responded to survey in 2014

\begin{tabular}{|c|c|c|c|c|c|c|c|c|c|c|c|c|c|}
\hline Country & $\begin{array}{c}\text { Total health } \\
\text { expenditure } \\
\text { as \% of } \\
\text { gross } \\
\text { domestic } \\
\text { product }\end{array}$ & $\begin{array}{c}\text { Public } \\
\text { health } \\
\text { expenditure } \\
\text { as } \% \text { of total } \\
\text { health } \\
\text { expenditure }\end{array}$ & $\begin{array}{l}\text { National TB } \\
\text { programme }\end{array}$ & $\begin{array}{c}\text { Central } \\
\text { unit }\end{array}$ & $\begin{array}{l}\text { TB control } \\
\text { and } \\
\text { elimination } \\
\text { plan }\end{array}$ & $\begin{array}{c}\text { Specific } \\
\text { targets for } \\
\text { TB control } \\
\text { and } \\
\text { elimination }\end{array}$ & $\begin{array}{c}\text { Specific } \\
\text { TB } \\
\text { budget }\end{array}$ & $\begin{array}{l}\text { Laboratory } \\
\text { external } \\
\text { quality } \\
\text { assessment } \\
\text { system }\end{array}$ & $\begin{array}{l}\text { Individual } \\
\text { case-based } \\
\text { electronic } \\
\text { database }\end{array}$ & $\begin{array}{c}\text { Directly } \\
\text { observed } \\
\text { treatment } \\
\text { for all or } \\
\text { selected } \\
\text { patients }\end{array}$ & $\begin{array}{c}\text { Free TB } \\
\text { diagnosis }\end{array}$ & $\begin{array}{l}\text { Free TB } \\
\text { treatment }\end{array}$ & $\begin{array}{c}\text { Special } \\
\text { incentive/ } \\
\text { enabler } \\
\text { for some } \\
\text { or all TB } \\
\text { patients }\end{array}$ \\
\hline Australia & 9 & 68 & No & No & Yes & Yes & No & Yes & Yes & Selected & $\begin{array}{l}\text { Yes, all } \\
\text { tested }\end{array}$ & Yes & No \\
\hline Austria & 9 & 76 & NA & NA & NA & NA & NA & NA & NA & Selected & NA & NA & NA \\
\hline Belgium & 11 & 76 & No & No & No & No & Yes & Yes & Yes & Selected & $\begin{array}{l}\text { Yes, all } \\
\text { tested }\end{array}$ & Yes & No \\
\hline Canada & 11 & 70 & No & No & Yes & Yes & No & Yes & No & Selected & $\begin{array}{l}\text { Yes, all } \\
\text { tested }\end{array}$ & Yes & No \\
\hline Cuba & 10 & 95 & Yes & Yes & Yes & Yes & Yes & Yes & Yes & All & $\begin{array}{l}\text { Yes, all } \\
\text { tested }\end{array}$ & Yes & Yes \\
\hline Cyprus & 7 & 43 & No & No & No & No & No & Yes & Yes & All & $\begin{array}{c}\text { Yes, if } \\
\text { confirmed }\end{array}$ & Yes & No \\
\hline Czech Rep. & 7 & 84 & No & No & No & No & No & Yes & Yes & Selected & $\begin{array}{l}\text { Yes, all } \\
\text { tested }\end{array}$ & Yes & No \\
\hline Denmark & 11 & 85 & No & No & No & No & No & Yes & Yes & Selected & $\begin{array}{l}\text { Yes, all } \\
\text { tested }\end{array}$ & Yes & No \\
\hline Finland & 9 & 75 & Yes & No & Yes & No & No & Yes & Yes & Selected & $\begin{array}{l}\text { Yes, all } \\
\text { tested }\end{array}$ & Yes & No \\
\hline France & 12 & 77 & Yes & Yes & Yes & No & Yes & Yes & Yes & Selected & $\begin{array}{l}\text { Yes, all } \\
\text { tested }\end{array}$ & Yes & No \\
\hline Germany & 11 & 76 & Yes & Yes & Yes & Yes & Yes & Yes & Yes & Selected & $\begin{array}{l}\text { Yes, all } \\
\text { tested }\end{array}$ & Yes & No \\
\hline Greece & 11 & 61 & No & No & No & No & No & Yes & Yes & NA & $\begin{array}{c}\text { Yes, other } \\
\text { criteria }\end{array}$ & $\mathrm{No}^{\#}$ & No \\
\hline Ireland & 9 & 70 & Yes & No & No & No & No & Yes & Yes & Selected & $\begin{array}{l}\text { Yes, all } \\
\text { tested }\end{array}$ & No" & Yes \\
\hline Israel & 8 & 62 & Yes & Yes & Yes & Yes & Yes & Yes & Yes & All & $\begin{array}{l}\text { Yes, all } \\
\text { tested }\end{array}$ & Yes & Yes \\
\hline Malta & 9 & 66 & Yes & Yes & Yes & Yes & No & No & Yes & Selected & $\begin{array}{l}\text { Yes, all } \\
\text { tested }\end{array}$ & Yes & Yes \\
\hline Netherlands & 12 & 86 & No & Yes & Yes & No & No & No & Yes & Selected & $\begin{array}{l}\text { Yes, other } \\
\text { criteria }^{+}\end{array}$ & $\mathrm{No}^{+}$ & Yes \\
\hline Norway & 9 & 86 & No & Yes & No & No & No & Yes & Yes & Selected & $\begin{array}{l}\text { Yes, all } \\
\text { tested }\end{array}$ & Yes & Yes \\
\hline Slovakia & 9 & 64 & Yes & Yes & Yes & No & Yes & Yes & Yes & Selected & $\begin{array}{l}\text { Yes, all } \\
\text { tested }\end{array}$ & Yes & No \\
\hline Slovenia & 9 & 73 & No & No & Yes & Yes & No & Yes & Yes & NA & $\begin{array}{l}\text { Yes, all } \\
\text { tested }\end{array}$ & Yes & No \\
\hline Sweden & 9 & 81 & No & No & No & No & No & Yes & Yes & No policy & $\begin{array}{l}\text { Yes, all } \\
\text { tested }\end{array}$ & Yes & No \\
\hline Switzerland & 11 & 65 & Yes & Yes & Yes & No & Yes & Yes & Yes & Selected & No & No & Yes \\
\hline USA & 18 & 46 & Yes & Yes & Yes & Yes & Yes & No & Yes & Selected & $\begin{array}{l}\text { Yes, all } \\
\text { tested }\end{array}$ & Yes & Yes \\
\hline
\end{tabular}

Data concern national levels. Based on the roles and responsibilities for the organisation and delivery of health services, country-level responses need to be interpreted with caution, especially for countries with a federal system of government. NA: not available or no answer. ${ }^{\#}$ : patient pays $25 \%$; ${ }^{\text {I: }}$ nominal fee of $€ 1.50$ on each medication dispensed; ${ }^{+}$: covered by health insurance, but patients must pay the first $€ 350$ of healthcare costs. 


\section{2) Address the most vulnerable and hard-to-reach groups}

As incidence decreases, TB becomes more and more concentrated in certain vulnerable groups, such as the poor, homeless people, migrants, people living with HIV/AIDS, people who use substances and alcohol harmfully, prisoners and marginalised groups. These groups often overlap, and they not only have a greater risk of developing TB, but also a greater risk of not accessing or adhering and responding to TB treatment. Moreover, TB can make the vulnerable more vulnerable through its aftermath, such as stigma and social isolation, financial burden, loss of employment, loss of housing, interruption of studies and deportation [3-7, 36, 40, 59-63].

In some low-incidence countries, indigenous populations (e.g. aboriginal people or First Nations) or certain ethnic minorities (e.g. Roma) have TB incidence rates that are much greater than the general population [60]. This may be due to a combination of compounded exposure to TB risk factors, poor healthcare access and, possibly, genetic factors [60]. Immigrants from high-incidence countries may or may not belong to the most vulnerable groups in their destination country, depending on the reason for migrating, their migration status and the conditions of migration [64].

TB incidence rates are higher in urban areas than in rural areas in many low-incidence countries [7, 61, $62,65,66]$. This is due to a congregation of certain vulnerable groups, including migrants. Health services are sometimes more fragmented in urban areas than in rural areas [65]. However, the indigenous populations of some of the low-incidence countries have most of their communities in remote rural areas lacking access to full services for diagnosis and treatment.

The elderly often have a greater TB incidence rate than younger individuals, due to a cumulative exposure and elevated risk of progression to active disease [67-69]. Many low-incidence settings have experienced a shifting of the burden of TB towards the oldest age groups, at least in the non-foreign-born population [70]. However, this is not seen consistently [71]. The rate of TB in the elderly depends largely on historical TB exposure in each birth cohort, and it will therefore vary with historical TB trends. Diagnosis of TB in the elderly is often delayed, especially since TB symptoms may be masked by other, more common conditions [72]. Treatment of active TB in the elderly presents special challenges due to comorbidities and general age-related vulnerability. Side-effects of TB medicines and other complications are also more common, which warrants close clinical monitoring [73]. Effectiveness and cost-effectiveness of systematic TB screening in selected groups of the elderly is uncertain $[74,75]$.

Young children are vulnerable because they have increased risk of TB disease once infected, as well as increased risk of severe disease, while the diagnosis of TB in children is often challenging [76-80]. Bacille Calmette-Guerin (BCG) vaccination has limited efficacy in preventing pulmonary TB but can effectively reduce the risk of severe disseminated forms of $\mathrm{TB}$ and their sequelae in children $[81,82]$. However, the risk-benefit ratio of BCG vaccination becomes increasingly unfavourable with decreasing TB transmission rate $[83-85]$.

\section{Key interventions}

Hard-to-reach groups with elevated TB risk and poor healthcare access need to be locally defined. Special attention is required for groups that may lack proper documentation and may not be covered by social health insurance or national health services. A patient-centred care and support approach that is sensitive and responsive to patients' needs [86] and founded on sound ethical principles [87] is crucial. Supportive treatment supervision by treatment partners must be carried out in a context-specific and patient-sensitive manner. Some people benefit from directly observed treatment.

More important than the supervision of treatment itself is the recognition and addressing of factors that may lead to poor access, treatment interruption and poor response [47]. Enabling interventions include removing financial barriers, making services user friendly (de-centralisation, conducive opening hours, appropriate staff attitude, addressing language barriers, etc.), providing social support, increasing awareness, alleviating stigma and discrimination and addressing comorbid conditions [86].

Social protection mechanisms are needed to prevent adverse social consequences and financial burden related to the direct and indirect costs of TB [88]. These include: 1) sickness insurance, disability pension, other cash transfers, housing support, vouchers or food packages; 2) legislation to protect people with TB from discrimination such as deportation or expulsion from workplaces, educational institutions or housing; and 3) instruments to protect and promote human rights, including addressing stigma and discrimination, with special attention to sex and ethnicity. All these measures require a multisectorial approach that ensures that social protection schemes are sufficiently TB sensitive, guaranteeing eligibility for all in need.

Specific training and TB awareness-raising activities for medical and social care staff in contact with groups at high risk should be considered, including training on how to help patients navigate and access 
health and social care. The planning and implementation should involve governmental health and social services as well as nongovernmental organisations and civil society, including formal and informal community leaders and health providers.

Social interventions need to go beyond people already ill with TB and also focus on the people and communities at risk through a "health-in-all-policies" approach [89]. Poverty alleviation reduces the risk of TB and helps improve access to health services and adherence. Prevention can also be enhanced through addressing direct risk factors for TB, including HIV [90], smoking [91], harmful use of alcohol [92] and drugs [93, 94], diabetes [35, 95] and malnutrition [96].

Special attention is required with regard to early diagnosis of active TB in the elderly and in children [97]. Detection and treatment of LTBI in child TB contacts is essential (see action area 4). Low-incidence countries should consider directing BCG vaccination to children in high-risk groups, or to phase out BCG vaccination entirely, depending on national TB epidemiology [83, 98].

\section{3) Address special needs of migrants and cross-border issues}

Global migration has dramatically increased in recent decades because of the changing global economy, war, civil unrest, socioeconomic inequities and ease of travel. It is unlikely that this trend will be reversed in the near future. Many migrants are at increased risk of ill health as a result of the poor conditions through which they travel and then work and live [99]. While traditionally viewed as a unidirectional phenomenon, migration has become increasingly circular and complex, underscoring the need to move beyond narrow unilateral approaches to migration and highlighting the linkage of good TB control in source countries with preventive interventions in receiving states $[99,100]$.

In many low-incidence countries, trends in TB incidence are driven largely by international migration dynamics [36, 101, 102]. With a few exceptions, TB incidence rates among the foreign born are several times higher than among indigenous, non-foreign-born people (table 4 and fig. 4). The rates of TB in specific migrant groups often correspond to those of their countries of origin $[103,104]$, while reactivation risk may increase due to socioeconomic vulnerability augmented by stressful migration conditions [105]. Some immigrant subgroups may also have a higher likelihood of not completing treatment once started, particularly if there are language difficulties [106]. TB in foreign-born persons represents, on average, $>50 \%$ of all TB cases in low-incidence countries, but varies widely from $0 \%$ to $90 \%$ (table 3 ).

TB is sometimes transmitted within migrant communities, but transmission from migrant groups into host country populations is normally limited [107-112].

People may migrate during TB treatment, or they may migrate to access TB care of perceived higher quality, particularly if they suffer from difficult-to-treat TB forms (multidrug-resistant (MDR) or extensively drug-resistant (XDR) TB) [113-116]. This creates challenges for treatment follow-up, continuity of care, contact investigation, outbreak management and surveillance. Insufficient coordination of TB care services across borders can lead to insufficient quality of care, continued transmission and incomplete TB surveillance [117].

\section{Key interventions}

The most essential action is to ensure that healthcare services are accessible to all migrants, and that care is patient centred and culturally sensitive, including efforts to overcome language and other barriers. Collaboration between countries and national legislation should guarantee the functionality and access to TB services without financial burden for all migrants regardless of status, including undocumented migrants and migrants without full residence status.

Epidemiological assessments should explore whether TB in migrants is a priority challenge and assess which groups of migrants have a high risk of TB. For this, detailed surveillance is essential, including disaggregated data on migrant groups and related variables.

Migrant communities should be empowered through social mobilisation and health communication. Sensitisation of medical and administrative personnel to health profiles and special needs of migrants is needed to build cultural competency. TB diagnosis, treatment and care for migrants should be integrated within general health services, while special efforts may be needed to reach migrants at centres for refugees or asylum seekers and other special settings.

Based on epidemiological assessment, systematic screening for active TB in migrants (pre-migration, at point of arrival or after arrival) may be considered within the country context and be coupled with careful evaluation of screening yield and impact [118]. Screening should be linked with follow-up or referral to the treatment programme. More research is needed to evaluate the effectiveness and cost-effectiveness of different screening approaches for each group of migrants, and it should consider health system, patient 
and societal perspectives [119]. Systematic screening in migrants does not exclude the possibility of occurrence of TB later; therefore, the continuous access to healthcare, individual follow-up and preventive interventions are important, whatever the screening system in place [120]. TB screening in migrants should follow established ethical principles for screening for infectious diseases and observe human rights principles [87]. It is particularly important to safeguard against stigma, discrimination and deportation [118].

Systematic screening for LTBI may also be considered along the migration pathway. LTBI screening, if done, should focus on risk groups based on the risk of exposure and the progression to disease [121]. LTBI screening should be linked to strategies for preventive treatment. These interventions are important elements of contact investigation and outbreak management for migrants as well as others (see action area 4$)$.

Pre-migration screening, if done, may require investment in diagnostic and treatment facilities in the countries of departure. Such capacity strengthening should ensure that benefits are shared with national TB programmes in the country where screening takes place, and good links must be established with the country's surveillance system.

It is important to establish cross-border referral systems with contact tracing and information sharing. For migrants with $\mathrm{TB}$, the right to complete treatment in the country where diagnosis is made should be ensured, or schemes should be put in place to ensure that patients moving during treatment can continue it while minimising the public health risk [36].

Bold intersectoral policies and systems are required to address underlying vulnerabilities in migrants that increase the risk of TB and of poor access to health services. Policy coherence and shared solutions need to be sought between health and non-health sectors such as immigration authorities, social services and the labour sector. Special social protection measures may be required for migrants with TB or at risk of getting TB.

\section{4) Undertake screening for active TB and LTBI in TB contacts and selected high-risk groups, and provide appropriate treatment}

Screening in high-risk groups can contribute to early detection of active TB. It has been implemented to various extents in different countries, but few report data on the yield and case detection contribution of such screening (table 7). There is a lack of good research demonstrating the impact of screening on transmission and incidence, and the cost-effectiveness, especially of insufficiently targeted screening, is questionable because of the large number of people needed to be screened to detect one case of TB in low-incidence settings [119]. Systematic screening for active TB therefore needs to be carefully targeted to the groups with the highest risk of TB, and projects should incorporate measurements of effectiveness [118, 122].

A limiting factor for the impact of screening for active TB on transmission is that transmission rates are already very low in low-incidence countries. The majority of incident TB cases are generated through reactivation of LTBI acquired abroad or domestically in a distant past [61, 123-125]. When transmission does occur, it is often in the form of limited outbreaks within the household, in healthcare facilities, or in congregate settings such as prisons or shelters, and more occasionally in pubs or schools [126-128]. Therefore, while screening for active TB and LTBI can potentially help stop ongoing outbreaks, the screening and management of LTBI in risk groups may be relatively more important [39]. However, the evidence for epidemiological impact of LTBI screening and treatment is very weak [121].

The risk of progression from LTBI to active disease is the highest for people with recent infection, such as TB contacts (especially children aged $<5$ years), other recent converters such as healthcare workers undergoing serial testing, and people with impaired immunity due to comorbid conditions, including HIV infection, or immunosuppressive treatments, such as tumour necrosis factor (TNF)- $\alpha$ inhibitors [120, 129-133].

LTBI can be effectively treated, but the decision to test and treat should be taken after evaluation of the risk-benefit trade-off, and only those with the highest risk of progression should be considered for screening and treatment. Currently, there is no ideal test that can accurately predict that risk. Treatment of LTBI with isoniazid has a $60-90 \%$ efficacy in clinical trials, but is associated with a small risk of hepatotoxicity that may result in a fatal outcome [73]. A 4-month rifampicin regimen [134], 3-month daily regimen with rifampicin and isoniazid or a 3-month weekly treatment with rifapentine and isoniazid seem to have similar efficacy and lower risk of severe adverse events [135].

An additional challenge is that adherence to treatment of LTBI is often poor [136-143], although in some countries and in some population groups completion rates of $80 \%$ are achieved [144, 145]. Shorter regimens may be associated with a significant increase in treatment completion rates. While there is some evidence from observational studies of the efficacy of treatment for LTBI for children exposed to 
TABLE 7 Screening strategies in 22 low-incidence countries that responded to survey in 2014

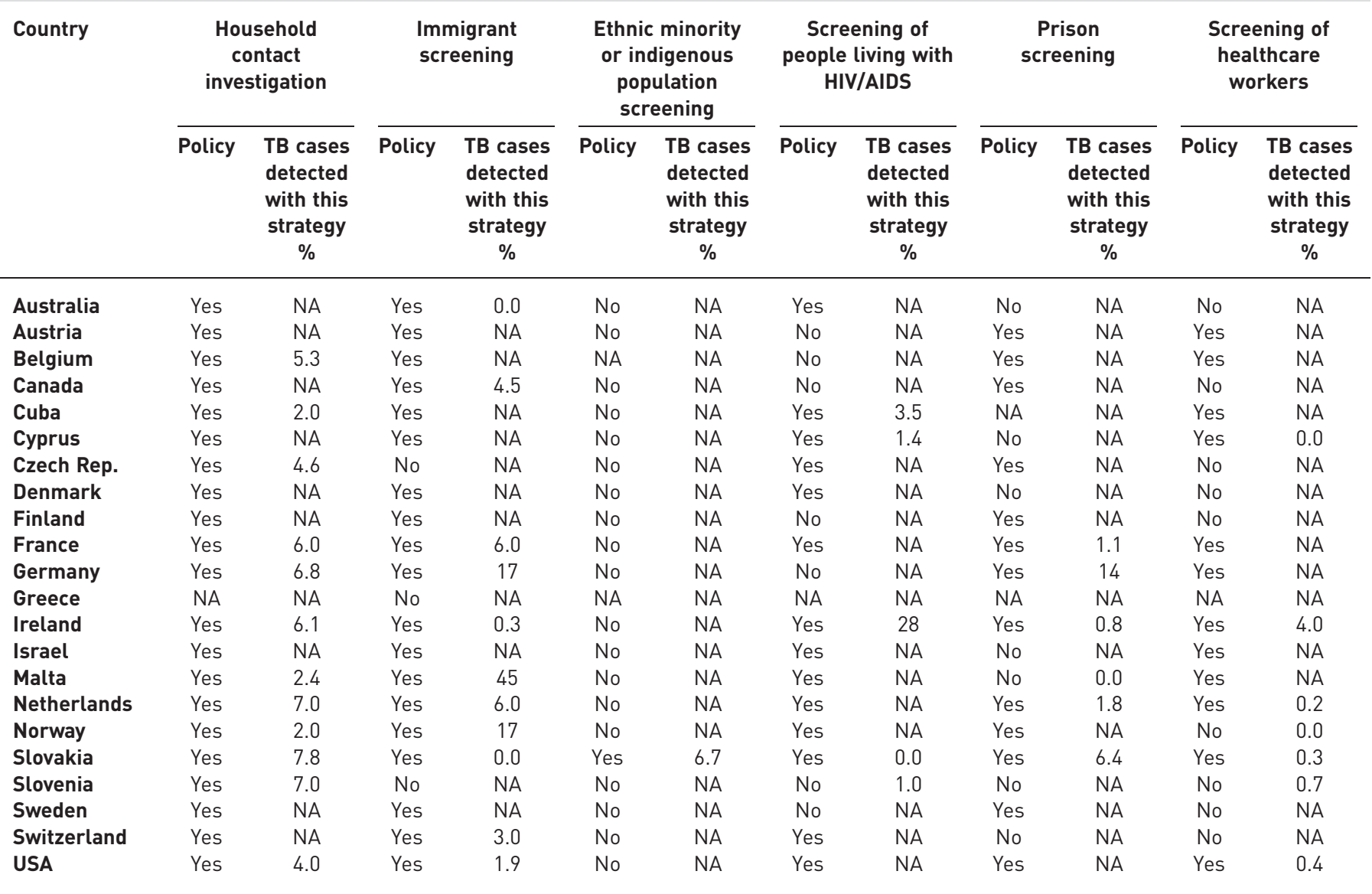

Data concern national levels. Based on the roles and responsibilities for the organisation and delivery of health services, country-level responses need to be interpreted with caution, especially for countries with a federal system of government. TB: tuberculosis; NA: not available or no answer.

MDR-TB [146, 147], the benefit of such treatment has yet to be evaluated through randomised controlled trials $[121]$.

Key interventions

While systematic screening for active TB in high-risk groups can potentially contribute to earlier detection of TB, ensuring universal access and correctly selecting people who should be tested for TB among those actively seeking care is the highest priority $[118,148]$.

Contact investigation, including source finding for recently infected cases, e.g. young children, should be performed routinely around each newly detected TB case and may expand to community contacts [149, 150]. Systematic screening should also be routine in people living with HIV and it should be a part of general health check-ups in people working in the mining industry and other silica-exposed occupations [118]. Real-time surveillance with mapping of cases in space and in time, preferably supported by genotyping, is required to identify an outbreak in a community, healthcare facility [151], correctional facility [152] or in other specific settings or risk groups $[153,154]$. Note that a disease outbreak is defined by the WHO as the occurrence of cases of disease in excess of what would normally be expected in a defined community, geographical area or season [155].

Other risk groups (not indicated by contact investigation or outbreak management), e.g. migrants, prisoners, homeless people, certain ethnic minorities, the elderly and people with immuno-compromising disorders or treatments, may be prioritised for systematic screening of active TB based on local TB epidemiology and an assessment of benefits, risks and costs [118]. General population screening (or screening in other groups than those at very high risk) should not be done in low-incidence countries, since there is weak evidence of epidemiological impact [119], it can be very expensive, and it is associated with a high risk of false-positive TB diagnosis when prevalence is low [156]. A national strategy for 
systematic screening for active TB in selected high-risk groups should include careful case-based surveillance that allows for monitoring and evaluation of the screening strategy and can guide reprioritisation and discontinuation of screening when the yield reaches a low level.

The general principles of screening for LTBI are that there should be a positive trade-off between benefits and harms for the individual, and that a decision to test is an intention to consider treatment if positive [121]. At an individual level, to be eligible for this intervention, the benefits of treatment should outweigh the risk of drug toxicity. Based on these considerations, systematic testing and treatment of LTBI should be done for people living with HIV, adult and child contacts of pulmonary TB cases, patients initiating anti-TNF- $\alpha$ treatment, patients receiving dialysis, patients preparing for organ or haematological transplantation, and patients with silicosis [121]. The evidence for benefits of LTBI treatment in other risk groups is very scarce. However, systematic testing and treatment of LTBI may also be considered for prisoners, health workers, migrants from high-TB-burden countries, homeless people and illicit drug users. Within these groups, priority must be given to those individuals with a history of recent conversion of the status of infection, tested either by interferon- $\gamma$ release assays or the tuberculin skin test, from negative to positive [121].

The following treatment options are currently recommended for the treatment of LTBI: 6 months of isoniazid or 9 months of isoniazid, or a 3-month regimen of weekly rifapentine plus isoniazid, or 3-4 months of isoniazid plus rifampicin, or 3-4 months of rifampicin alone. Rifampicin- and rifapentine-containing regimens should be prescribed with caution to people living with HIV who are on antiretroviral treatment, due to potential drug-to-drug interactions. Individuals receiving treatment for LTBI should receive regular clinical monitoring through monthly visits to healthcare providers [121].

\section{5) Optimise the prevention and care of drug-resistant TB}

Drug-resistant forms of TB constitute a particularly grave threat to future TB elimination efforts for lowand high-incidence countries alike $[36,157,158]$. Further spread and amplification of drug resistance could undo previous TB control efforts by rendering the disease yet again incurable $[33,159]$.

Countries that have reduced TB incidence to low levels usually observe a concentration of their TB caseload in patient groups at risk of poor treatment adherence and thus of acquired drug resistance [62]. As more countries are destined to follow a declining trend in TB caseloads, a heightened vigilance for the emergence and transmission of drug-resistant strains is needed.

People diagnosed with MDR-TB often face particular challenges related to the long disease history and the lengthy and complex treatment regimens. It is very difficult and resource demanding to manage MDR-TB, for both patients and the health system, and social and financial support are often needed to enable access and ensure adherence [160-164].

\section{Key interventions}

The "test and treat" approach should allow for the early identification not only of TB but also of the resistance patterns that determine the type of treatment required; this implies systematic and universal drug susceptibility testing of all bacteriologically positive TB cases to determine the most effective treatment based on the resistance pattern [160]. Optimal patient-centred support is particularly important for people with MDR-TB or XDR-TB, who face longer and more challenging treatments $[15,161,162$, 165]. Good clinical management for patients with drug-resistant TB should be based upon the expertise of medical specialists from paediatrics, HIV, psychiatry, substance-abuse and surgery, among others. These services are ideally provided through an expert committee or a consilium (a team of experts recommending the best management of clinically complex and difficult-to-treat cases) $[114,115]$.

A patient-centred approach that is sensitive and responsive to patient needs will require a multidisciplinary input. Support measures, beyond the treatment regimen itself, must be tailored to suit the needs of the patient. Social networks will be needed to provide comprehensive care to patients with drug-resistant TB, using both ambulatory and hospital-based models of care as required. Directly observed treatment has a role in improving adherence to treatment, alongside other supportive and educational measures. Special financial enablers to patients and their carers may become particularly viable when TB control hinges upon a smaller number of cases completing their treatment as prescribed.

Treatment and support must also extend beyond cure to address any sequelae associated with TB. Moreover, access to comprehensive palliative and end-of-life care is essential, particularly for people with XDR-TB who do not respond to any treatment $[160,166,167]$.

Current treatment regimens for drug-resistant TB remain unsatisfactory in terms of duration, safety, effectiveness and cost $[157,163,168]$. New drugs have recently come on the market [169-172], but 
further research into safer, affordable and more effective medicines are key to improving treatment outcomes [173]. Linkages with existing pharmacovigilance mechanisms will contribute to promoting safer use and management of medicines and side-effects. Resistance will develop to the new anti-TB medicines. Closer surveillance of drug resistance in the community will therefore be required. Rational use of drugs backed by properly enforced regulations and measures to assist clinical decisions and guarantee the quality of drug formulations may forestall the generation of resistance to new drugs [174].

\section{6) Ensure continued surveillance and programme monitoring and evaluation, with individual case-based data management}

Real-time, case-based surveillance is essential to enable a tailored response that meets the needs of special groups and that allows continual reprioritisation and re-targeting of special interventions. As TB caseloads are reduced it will become more crucial not to miss any new patients, particularly those who are more likely to die, to infect others, or to have drug resistance. Public health efforts thus need to be maintained through a framework of complementary measures, both regulatory and enabling, that promote an adequate level of vigilance.

\section{Key interventions}

The notification of TB should be compulsory at all levels and should discriminate between different forms of disease, including drug-resistant forms. The practice of recording individual TB patient data should be maintained and strengthened [175]. Having fewer patients may make it more feasible to collect more variables at a more frequent rate for each one of them. This will be useful not only for the patient under treatment but also for the study of risk factors and disease determinants [176]. Special attention to TB rates in children [77], disaggregation according to risk profile, and monitoring of people receiving LTBI treatment can also help determine trends in transmission and incidence, and help assess impact and refine intervention packages. Data on the location of patient residence permit spatio-temporal studies of TB hotspots for targeted public health action [177-179]. These become more pertinent as an epidemic recedes, when cases are fewer but more concentrated in space and time. Unique identifiers and biometric data may help trace patients, but confidentiality must be safeguarded.

Surveillance systems should ensure the quality of data with respect to completeness, timeliness, consistency and validity, with periodic assessment of the standards and benchmarks of the TB surveillance system [23]. Core indicators based on the context of the country need to be developed. They should particularly address the monitoring of ongoing transmission. The future should see more streamlining in the interoperable linkage of data across facilities and systems, such as hospitals, laboratories, mortality registers and patient management systems, to ensure that more comprehensive and timely information is made available to the clinicians and public health practitioners. Linkages with other disease surveillance, such as that for HIV and other TB comorbidities including diabetes [35], should be explored.

Surveillance practitioners need to keep abreast of advances in TB diagnostic techniques, the results of which are becoming increasingly automatically generated, as well as of the state-of-the-art information and communication technology required to capture and transmit data rapidly. Future surveillance systems need to exploit the state of the science in information technology. These methods can include linking up patient data (demographic, clinical, geo-positioning, vital statistic and socioeconomic information), with systematic DNA fingerprinting of strains when investigating outbreaks or linked cases. Information on drug-related harms is destined to become more important when newer medicines are used ahead of the completion of phase III trials; pharmacovigilance could be routinely integrated in the monitoring framework of TB [180].

\section{7) Invest in research and new tools}

Revolutionary new technologies and service delivery models are needed to achieve TB elimination. This will require an intensification of research, from fundamental research to drive innovations to operational and health systems research to improve current programmatic performance. Presently, TB research is grossly under-funded, which has resulted in a meagre pipeline of new technologies for TB diagnosis, treatment and prevention [181]. In order for further progress to be made, investments are required in both research and capacity building to implement trials in accordance with international standards [182].

\section{Key interventions}

Low-incidence, high-income countries can contribute substantially to the required international financial and technical support and collaboration for fundamental and clinical research towards new tools, as well as epidemiological, social and operational research to enhance uptake and to enable equitable access to new and existing technologies. Broad-based, concerted effort is needed to develop research capacity, allocate appropriate resources and encourage stakeholders to work together. A prominent role should be assigned to advocacy for research. 
Of particular relevance for low-incidence countries is the development of better tools for screening in high-risk groups, both for LTBI and active TB. The prospect of TB prevention would be improved by a rapid, accurate test that could both diagnose LTBI and forecast the likelihood of progression to active disease, and by briefer, safer and more efficacious treatment regimens [183]. More research and investments are required to address a series of major scientific challenges and to set the priorities for future TB vaccine research [184]. A post-exposure vaccine that prevents the disease in latently infected individuals would be a huge advancement towards TB elimination. This would be favourably complemented with the development of a pre-exposure vaccine that would prevent TB infection at population level [185]. Better, safer and shorter treatment for drug-resistant TB is urgently needed. Investments are required in both research and capacity building to implement trials in accordance with international standards. Markers of treatment outcome should be developed to accelerate the conduct of clinical trials, and reliable, rapid and cost-effective diagnostics/markers for drug resistance are needed [182].

Fostering better and more relevant research in epidemiology, programme operation, health systems and social science will help implementation and contribute to the development of both national and global policies. For this purpose, good systems for research prioritisation, planning and implementation need to be in place at country level as well as internationally. Better strategies should be developed to discover and target interventions using innovative tools for high-risk groups.

\section{8) Support global TB control}

In a globalised world, sustained national TB elimination cannot be achieved without a major reduction of the burden of $\mathrm{TB}$ worldwide. On average, $>50 \%$ of cases in low-incidence countries arise in high-TB-burden countries. The countries with the highest TB burden are also the poorest countries, most of which have the least well equipped health systems. Providing support to efforts to fully implement the global strategy especially in these countries can benefit the low-incidence countries that often attract migrants from less privileged countries. Such investment has been shown to be cost-effective in terms of potential impact on domestic TB rates in low-incidence settings [29].

\section{Key interventions}

Low-incidence countries should support the implementation of all aspects of the global TB strategy, through bilateral and multinational mechanisms. This can be in the form of financial support, technical assistance, technology exchange, research collaboration and capacity strengthening.

Raising additional financial resources for domestic as well as international efforts for TB care and prevention will require that $\mathrm{TB}$ continues to remain high in the international public health agenda. Active engagement and support from low-incidence countries to promote global TB advocacy could give the required visibility to sustained efforts essential for TB elimination.

Continuous monitoring will be required to measure progress and ensure that the implementation of the global strategy is on track. For this purpose, all countries will need to continue to participate in, and benefit from, global surveillance, monitoring and evaluation for TB prevention, care and control.

\section{The way forward: engaging national and international partners for full implementation}

Moving towards TB elimination requires commitment and political leadership from national and international stakeholders. First of all, governance, leadership, funding and accountability arrangements will require national and local government to take a lead role. The involvement of a wider partnership may help sway political and public health opinion to support the development of an evidence-based national elimination plan that is resourced, implemented and monitored.

Ideally, the national effort should be supported by a multidisciplinary and multiprofessional group that includes professional societies, civil society organisations, private sector health organisations and all relevant government departments that have a role in TB elimination, including those responsible for medical research, public health, healthcare, housing, justice, immigration and social welfare. Professional societies may be able to advise on approaches that may be used to overcome potential implementation difficulties.

As the burden of TB remains strongly determined by social factors, inevitably TB control must also include social interventions that require broad-based support to maximise impact. Health professionals need effective partnerships with social services and with local community groups able to provide an advocacy platform for patients. The trust and support of affected communities is the key to early diagnosis, engagement with treatment services, and sustained commitment to address the wider social determinants of TB.

International partnerships are as important as national partnerships. Collaboration with national authorities of other low-incidence countries, international organisations, technical partners and 
international professional associations will become more important as TB incidence decreases further. Engagement of international consortia of medical and pharmaceutical faculties and federations of professional organisations is important to maintain interest in TB as a major global health issue, streamline medical practice and stimulate research. Joining forces will bundle available knowledge and expertise and help develop common strategies for both low- and high-incidence countries that are progressing towards elimination. Platforms to exchange countries' experience, best practices and challenges will help countries to adjust their programmes and interventions to meet the demands of the changing epidemic, while building unified mechanisms to address regional and cross-border problems in a compatible way.

International organisations, technical partners and international professional associations have distinct and yet complementary roles in TB control, including policy development, surveillance, provision of professional training courses, facilitation of exchange visits, research, and publication of scientific journals focused on TB control issues relevant for low-incidence settings. Collaboration and fostering strong partnerships between national and international stakeholders, including beyond TB programmes and health sectors, will pave the way to accelerate towards elimination of TB in both low- and high-incidence countries.

\section{Acknowledgements}

The authors wish to thank Andrea Corazza (Global Health Advocates, Brussels, Belgium) and Nathalie Likhite (Global TB Programme, World Health Organization (WHO), Geneva, Switzerland) for their contribution to the development of the manuscript. Knut Lönnroth, Dennis Falzon, Alberto Matteelli, Diana Weil, Mohamed Abdel Aziz, Vineet Bhatia, Andrei Dadu, Hannah M. Dias, Haileyesus Getahun, Philippe Glaziou, Mirtha del Granado, Nobuyuki Nishikiori, Giorgia Sulis, Mukund Uplekar and Mario C. Raviglione are staff members of the WHO. They alone are responsible for the views expressed in this publication and they do not necessarily represent the decisions or policies of the WHO.

\section{References}

1 World Health Organization. Global tuberculosis report 2014. WHO/HTM/TB/2014.08. Geneva, World Health Organization, 2014.

2 Blasi F, Barnes PJ, Gaga M, et al. Future directions for the ERS: presidential plans. Eur Respir J 2013; 42: 875-880.

3 Broekmans JF, Migliori GB, Rieder HL, et al. European framework for tuberculosis control and elimination in countries with a low incidence. Recommendations of the World Health Organization (WHO), International Union Against Tuberculosis and Lung Disease (IUATLD) and Royal Netherlands Tuberculosis Association (KNCV) Working Group. Eur Respir J 2002; 19: 765-775.

4 Lönnroth K, Jaramillo E, Williams BG, et al. Drivers of tuberculosis epidemics: the role of risk factors and social determinants. Soc Sci Med 2009; 68: 2240-2246.

5 Zumla A, Atun R, Maeurer M, et al. Eliminating tuberculosis and tuberculosis-HIV co-disease in the 21 st century: key perspectives, controversies, unresolved issues, and needs. J Infect Dis 2012; 205: Suppl. 2, S141-S146. Story A, Murad S, Roberts W, et al. Tuberculosis in London: the importance of homelessness, problem drug use and prison. Thorax 2007; 62: 667-671.

$7 \quad$ Ali M. Treating tuberculosis as a social disease. Lancet 2014; 383: 2195.

8 World Health Organization 67th World Health Assembly. Global strategy and targets for tuberculosis prevention, care and control after 2015. A67/11. Geneva, World Health Organization, 2014.

9 Raviglione MC, Ditiu L. Setting new targets in the fight against tuberculosis. Nat Med 2013; 19: 263

10 Clancy L, Rieder HL, Enarson DA, et al. Tuberculosis elimination in the countries of Europe and other industrialized countries. Eur Respir J 1991; 4: 1288-1295.

11 European Centre for Disease Prevention and Control. Framework Action Plan to Fight Tuberculosis in the European Union. Stockholm, ECDC, 2008.

12 Centers for Disease Control (CDC). A strategic plan for the elimination of tuberculosis in the United States. MMWR Morb Mortal Wkly Rep 1989; 38: 269-272.

13 Tuberculosis elimination revisited: obstacles, opportunities, and a renewed commitment. Advisory Council for the Elimination of Tuberculosis (ACET). MMWR Recomm Rep 1999; 48; 1-13.

14 D'Ambrosio L, Dara M, Tadolini M, et al. Tuberculosis elimination: theory and practice in Europe. Eur Respir J 2014; 43: 1410-1420.

15 Migliori GB, Zellweger JP, Abubakar I, et al. European Union Standards for Tuberculosis Care. Eur Respir J 2012; 39: 807-819.

16 Hopewell PC, Fair EL, Uplekar M. Updating the International Standards for Tuberculosis Care. Entering the era of molecular diagnostics. Ann Am Thorac Soc 2014; 11: 277-285.

17 World Health Organization. Towards TB elimination: an action framework for low-incidence countries. WHO/ HTM/TB/2014.13. Geneva, World Health Organization, 2014.

18 World Health Organization. WHO publications on tuberculosis. http://who.int/tb/publications/en/

19 Lönnroth K, Migliori GB, Raviglione M. Towards tuberculosis elimination in low-incidence countries: reflections from a global consultation. Ann Intern Med 2014; 161: 670-671.

20 World Health Organization. Global TB database. Available from http://who.int/tb/country/data/download/en/ Date last accessed: October 23, 2014.

21 Mor Z, Migliori GB, Althomsons SP, et al. Comparison of tuberculosis surveillance systems in low-incidence industrialised countries. Eur Respir J 2008; 32: 1616-1624.

22 Veen J, Migliori GB, Raviglione M, et al. Harmonisation of TB control in the WHO European region: the history of the Wolfheze Workshops. Eur Respir J 2011; 37: 950-959.

23 World Health Organization. Standards and benchmarks for tuberculosis surveillance and vital registration systems: checklist and user guide. WHO/HTM/TB/2014.02. Geneva, World Health Organization, 2014. 
World Health Organization. Assessing tuberculosis under-reporting through inventory studies. WHO/HTM/TB/ 2012.12. Geneva, World Health Organization, 2012.

Voniatis C, Migliori GB, Voniatis M, et al. Tuberculosis elimination: dream or reality? The case of Cyprus. Eur Respir J 2014; 44: 543-546.

McKeown T, Record RG. Reasons for the decline of mortality in England and Wales during the nineteenth century. Popul Stud 1962; 16: 94-122.

Fairchild A, Oppenheimer M. Public health nihilism vs pragmatism: history, politics, and the control of tuberculosis. Am J Public Health 1998; 88: 1105-1117.

Ploubidis GB, Palmer MJ, Blackmore C, et al. Social determinants of tuberculosis in Europe: a prospective ecological study. Eur Respir J 2012; 40: 925-930.

Schwartzman K, Oxlade O, Barr RG, et al. Domestic returns from investment in the control of tuberculosis in other countries. N Engl J Med 2005; 353: 1008-1020.

World Health Organization. Draft global strategy and targets for tuberculosis prevention, care and control after 2015. Report by the Secretariat. A67/11. Geneva, World Health Organization, 2014. http://apps.who.int/gb/ ebwha/pdf_files/WHA67/A67_11-en.pdf

Frieden TR, Fujiwara PI, Washko RM, et al. Tuberculosis in New York City - turning the tide. N Eng J Med 1995; 333: 229-233.

Zumla A. The white plague returns to London - with a vengeance. Lancet $2011 ; 377$ : 10-11.

Nathanson E, Nunn P, Uplekar M, et al. MDR tuberculosis - critical steps for prevention and control. $N$ Engl J Med 2010; 363: 1050-1058.

Creswell J, Raviglione M, Ottmani S, et al. Tuberculosis and noncommunicable diseases: neglected links and missed opportunities. Eur Respir J 2011; 37: 1269-1282.

Lönnroth K, Roglic G, Harries AD. Improving tuberculosis prevention and care through addressing the global diabetes epidemic: from evidence to policy and practice. Lancet Diabetes Endocrinol 2014; 2: 730-739.

Dara M, de Colombani P, Petrova-Benedict R, et al. Minimum package for cross-border TB control and care in the WHO European region: a Wolfheze consensus statement. Eur Respir J 2012; 40: 1081-1090.

Arinaminpathy N, Dye C. Health in financial crises: economic recession and tuberculosis in Central and Eastern Europe. J R Soc Interface 2010; 7: 1559-1569.

Reeves A, Basu S, McKee M, et al. Social protection and tuberculosis control in 21 European countries, 19952012: a cross-national statistical modelling analysis. Lancet Infect Dis 2014; 14: 1105-1112.

Diel R, Loddenkemper R, Zellweger JP, et al. Old ideas to innovate tuberculosis control: preventive treatment to achieve elimination. Eur Respir J 2013; 42: 785-801.

Lönnroth K, Castro KG, Chakaya JM, et al. Tuberculosis control and elimination 2010-50: cure, care, and social development. Lancet 2010; 375: 1814-1829.

Zenner D, Southern J, van Hest R, et al. Active case finding for tuberculosis among high-risk groups in low-incidence countries. Int J Tuberc Lung Dis 2013; 17: 573-582.

Organización Panamericana de la Salud. Programa regional de la tuberculosis. Informe de la IV reunión de países de baja prevalencia [Regional tuberculosis programme. Report of the 4th meeting of low-prevalence countries]. San José, Costa Rica, December 7-8, 2006. Washington, OPS/OMS, 2006.

World Health Organization. The World Health Report. Health systems financing: the path to universal coverage. Geneva, World Health Organization, 2010.

Collinson S, Ward R. A nurse-led response to unmet needs of homeless migrants in inner London. Br J Nurs 2010; 19: 36-41.

Klinkenberg E, Manissero D, Semenza JC, et al. Migrant tuberculosis screening in the EU/EEA: yield, coverage and limitations. Eur Respir J 2009; 34: 1180-1189.

Abubakar I, Stagg HR, Cohen T, et al. Controversies and unresolved issues in tuberculosis prevention and control: a low-burden-country perspective. J Infect Dis 2012; 205: Suppl. 2, S293-S300.

Chemtob D, Weiser S, Yitzhak I, et al. Medical anthropology - an important adjunct to international tuberculosis control. In: Reichman LB, Hershfield ES, eds. Tuberculosis: A Comprehensive International Approach. 2nd Edn. New York, Marcel Dekker, 2000; pp. 745-770.

World Health Organization. Stop TB Policy Paper. Contributing to health system strengthening. Guiding principles for national tuberculosis programmes. WHO/HTM/TB/2008.400. Geneva, World Health Organization, 2008.

Sotgiu G, D’Ambrosio L, Centis R, et al. Availability of anti-tuberculosis drugs in Europe. Eur Respir J 2012; 40: 500-503.

Centers for Disease Control and Prevention (CDC). Impact of a shortage of first-line antituberculosis medication on tuberculosis control - United States, 2012-2013. MMWR Morb Mortal Wkly Rep 2013; 62: 398-400.

Centers for Disease Control and Prevention (CDC). Extent and effects of recurrent shortages of purified-protein derivative tuberculin skin test antigen solutions - United States, 2013. MMWR Morb Mortal Wkly Rep 2013; 62: 1014-1015.

2 Baussano I, Abbona F, Veljkovic A, et al. Incidenza della tubercolo nella Regione Piemonte nel periodo 20012003 [Incidence of tuberculosis in Piedmont Region in the period 2001-2003]. Epidemiol Prev 2008; 32: 85-92. van Hest NA, Story A, Grant AD, et al. Record-linkage and capture-recapture analysis to estimate the incidence and completeness of reporting of tuberculosis in England 1999-2002. Epidemiol Infect 2008; 136: 1606-1616. van Hest NA, Smit F, Baars HW, et al. Completeness of notification of tuberculosis in The Netherlands: how reliable is record-linkage and capture-recapture analysis? Epidemiol Infect 2007; 135: 1021-1029.

World Health Organization. Public-private mix for TB care and control: a toolkit. WHO/HTM/TB/2010.12. Geneva, World Health Organization, 2010.

Centers for Disease Control and Prevention. Regional Training and Medical Consultation Centers (RTMCCs). Date last updated: November 25, 2013. Date last accessed: October 23, 2014.

World Health Organization. A Roadmap for Ensuring Quality Tuberculosis Diagnostics Services within National Laboratory Strategic Plans. Geneva, World Health Organization, 2010.

World Health Organization. Framework for conducting reviews of tuberculosis programmes. WHO/HTM/TB/ 2014.05. Geneva, World Health Organization, 2014. 
Chemtob D, Leventhal A, Weiler-Ravell D. Screening and management of tuberculosis in immigrants: the challenge beyond professional competence. Int J Tuberc Lung Dis 2003; 7: 959-966.

60 Tollefson D, Bloss E, Fanning A, et al. Burden of tuberculosis in indigenous peoples globally: a systematic review. Int J Tuberc Lung Dis 17: 1139-1150.

61 De Vries G, van Hest NAH, Baars HW, et al. Factors associated with the high tuberculosis case rate in an urban area. Int J Tuberc Lung Dis 2010; 14: 859-865.

62 De Vries G, Aldridge RW, Cayla JA, et al. Epidemiology of tuberculosis in big cities of the European Union and European Economic Area countries. Euro Surveill 2014; 19: pii 20726.

63 Verver S, Veen J. Tuberculosis control and migration. In: Raviglione, ed. TB: a Comprehensive International Approach. New York, Informa Healthcare, 2006.

64 Diel R, Rüsch-Gerdes S, Niemann S. Molecular epidemiology of tuberculosis among immigrants in Hamburg, Germany. J Clin Microbiol 2004; 42: 2952-2960.

65 van Hest NA, Aldridge RW, de Vries G, et al. Tuberculosis control in big cities and urban risk groups in the European Union: a consensus statement. Euro Surveill 2014; 19: pii 20728.

66 Kirby T. Tuberculosis rates unacceptably high in UK cities. Lancet Infect Dis 2013; 13: 836-837.

67 Fortin CF, McDonald PP, Lesur O, et al. Aging and neutrophils: there is still much to do. Rejuvenation Res 2008; 11: $873-882$.

68 Uyemura K, Castle SC, Makinodan T. The frail elderly: role of dendritic cells in the susceptibility of infection. Mech Ageing Dev 2002; 123: 955-962.

69 Jeon CY, Murray MB. Diabetes mellitus increases the risk of active tuberculosis: a systematic review of 13 observational studies. PLoS Med 2008; 5: e152.

70 Borgdorff MW, van der Werf MJ, de Haas PE, et al. Tuberculosis elimination in the Netherlands. Emerg Infect Dis 2005; 11: 597-602.

71 Centers for Disease Control and Prevention (CDC). Reported Tuberculosis in the United States, 2012. Atlanta, US Dept of Health and Human Services, CDC, 2013.

72 Schaaf HS, Collins A, Bekker A, et al. Tuberculosis at extremes of age. Respirology 2010; 15: 747-763.

73 Smieja MJ, Marchetti CA, Cook DJ, et al. Isoniazid for preventing tuberculosis in non-HIV infected persons. Cochrane Database Syst Rev 2000; 2: CD001363.

74 Verma G, Chuck AW, Jacobs P. Tuberculosis screening for long-term care: a cost-effectiveness analysis. Int J Tuberc Lung Dis 2013; 17: 1170-1177.

75 Schwartzman K, Dowdy D. The eye of the beholder: tuberculosis screening for elderly long-term care residents. Int J Tuberc Lung Dis 2013; 17: 1121.

Brodie D, Schluger NW. The diagnosis of tuberculosis. Clin Chest Med 2005; 26: 247-271.

Haas W. High time to tackle childhood tuberculosis. Euro Surveill 2011; 16: pii 19827.

Newton SM, Brent AJ, Anderson S, et al. Paediatric tuberculosis. Lancet Infect Dis 2008; 8: 498-510.

Ducomble T, Tolksdorf K, Karagiannis I, et al. The burden of extrapulmonary and meningitis tuberculosis: an investigation of national surveillance data, Germany, 2002 to 2009. Euro Surveill 2013; 18: pii 20436.

80 Sanchini A, Fiebig L, Drobniewski F, et al. Laboratory diagnosis of paediatric tuberculosis in the European Union/ European Economic Area: analysis of routine laboratory data, 2007 to 2011. Euro Surveill 2014; 19: pii 20744.

81 Colditz GA, Berkey CS, Mosteller F, et al. The efficacy of bacillus Calmette-Guerin vaccination of newborns and infants in the prevention of tuberculosis: meta-analyses of the published literature. Pediatrics 1995; 96: 29-35.

82 Bourdin Trunz B, Fine PE, Dye C. Effect of BCG vaccination on childhood tuberculous meningitis and miliary tuberculosis worldwide: a meta-analysis and assessment of cost-effectiveness. Lancet 2006; 367: 1173-1180.

83 Manissero D, Lopalco PL, Levy-Bruhl D, et al. Assessing the impact of different BCG vaccination strategies on severe childhood TB in low-intermediate prevalence settings. Vaccine 2008; 26: 2253-2259.

84 Guthmann JP, Chauvin P, Le Strat Y, et al. Family history of immigration from a tuberculosis endemic country and low family income are associated with a higher BCG vaccination coverage in Ile-de-France region, France. Vaccine 2013; 31: 5666-5671.

85 Nguipdop-Djomo P, Mangtani P, Pedrazzoli D, et al. Uptake of neonatal BCG vaccination in England: performance of the current policy recommendations. Thorax 2014; 69: 87-89.

86 Tuberculosis Coalition for Technical Assistance (TBCTA). Patient Centered Approach Strategy. The Hague, TBCTA, 2011.

87 World Health Organization. Guidance on ethics of tuberculosis prevention, care and control. WHO/HTM/TB/ 2010.16. Geneva, World Health Organization, 2010.

88 Lönnroth K, Glaziou P, Weil D, et al. Beyond UHC: monitoring health and social protection coverage in the context of tuberculosis care and prevention. PLoS Med 2014; 11: e1001693.

89 Lönnroth K, Jaramillo E, Williams BG, et al. Tuberculosis - the role of risk factors and social determinants. In: Blas E, Sivasankara Kurup A, eds. Priority Public Health Conditions: From Learning to Action on Social Determinants of Health. Geneva, World Health Organization, 2010.

90 World Health Organization. WHO policy on collaborative TB/HIV activities: guidelines for national programmes and other stakeholders. WHO/HTM/TB/2012.1. Geneva, World Health Organization, 2012.

91 World Health Organization, International Union against Tuberculosis and Lung Disease. A WHO/The Union Monograph on TB and Tobacco Control. WHO/HTM/TB/2007.390. Geneva, World Health Organization, 2008.

92 Rehm J, Samokhvalov AV, Popova S, et al. The association between alcohol use, alcohol use disorders and tuberculosis (TB). A systematic review? BMC Public Health 2009; 9: 450.

93 World Health Organization. Policy guidelines for collaborative TB and HIV services for injecting and other drug users: an integrated approach. WHO/HTM/TB/2008.404. Geneva, World Health Organization, 2008.

94 Chemtob D, Levy A. Rationale and staff evaluation of using a "therapeutic milieu" for substance users within a tuberculosis ward. Subst Use Misuse 2009; 44: 672-683.

95 World Health Organization, International Union against Tuberculosis and Lung Disease. Collaborative framework for care and control of tuberculosis and diabetes. WHO/HTM/TB/2011.15. Geneva, World Health Organization, 2011.

96 World Health Organization. Guideline: Nutritional care and support for people with tuberculosis. Geneva, World Health Organization, 2013. 
World Health Organization. Guidance for national tuberculosis programmes on the management of tuberculosis in children. 2nd Edn. WHO/HTM/TB/2014.03. Geneva, World Health Organization, 2014.

World Health Organization. BCG vaccine. WHO position paper. Wkly Epidemiol Rec 2004; 79: 27-38.

World Health Organization. Health of Migrants. Report by the Secretariat. A61/12. Geneva, World Health Organization, 2008 .

Med 2011; 8: e1001034. Arshad S, Bavan L, Gajari K, et al. Active screening at entry for
systematic review and meta-analysis. Eur Respir J 2010; 35: 1336-1345. tuberculosis. Expert Rev Anti Infect Ther 2013; 11: 137-146.

\section{Sandgren} populations in the EU/EEA: a systematic review. Eur Respir J 2014; 43: 1159-1171.

Fattorini L, Mustazzolu A, Piccaro G, et al. Drug-resistant tuberculosis among foreign-born persons in Italy. Eur Respir J 2012; 40: 497-500.

Moore-Gillon J, Davies PD, Ormerod LP. Rethinking TB screening: politics, practicalities and the press. Thorax 2010; 65: 663-665.

Helbling P, Medinger C, Altpeter E, et al. Outcome of treatment of pulmonary tuberculosis in Switzerland in 1996. Swiss Med Wkly 2002; 132: 517-522.

Lambregts-van Weezenbeek CS, Sebek MM, van Gerven PJ, et al. Tuberculosis contact investigation and DNA fingerprint surveillance in The Netherlands: 6 years' experience with nation-wide cluster feedback and cluster monitoring. Int J Tuberc Lung Dis 2003; 7: Suppl 3, S463-S470.

Dahle UR, Eldholm V, Winje BA, et al. Impact of immigration on the molecular epidemiology of Mycobacterium tuberculosis in a low-incidence country. Am J Respir Crit Care Med 2007; 176: 930-935.

Jasmer RM, Hahn JA, Small PM, et al. A molecular epidemiologic analysis of tuberculosis trends in San Francisco, 1991-1997. Ann Intern Med 1999; 130: 971-978.

Goldblatt D, Rorman E, Chemtob D, et al. Molecular epidemiology and mapping of tuberculosis in Israel: do migrants transmit the disease to locals? Int J Tuberc Lung Dis 2014; 18: 1085-1091.

Kamper-Jorgensen Z, Andersen AB, Kok-Jensen A, et al. Migrant tuberculosis: the extent of transmission in a low burden country. BMC Infect Dis 2012; 12: 60 .

Borgdorff MW, Nagelkerke N, van Soolingen D. Analysis of tuberculosis transmission between nationalities in the Netherlands in the period 1993-1995 using DNA fingerprinting. Am J Epidemiol 1998; 147: $187-195$.

Codecasa LR, Ciconali G, Mazzola E, et al. Managing an extensively drug-resistant tuberculosis outbreak: the public health face of the medal. Eur Respir J 2015; 45: 292-294.

Esposito S, D’Ambrosio L, Tadolini M, et al. ERS/WHO Tuberculosis Consilium assistance with extensively drug-resistant tuberculosis management in a child: case study of compassionate delamanid use. Eur Respir J 2014; 44: 811-815.

D'Ambrosio L, Tadolini M, Dupasquier S, et al. ERS/WHO tuberculosis consilium: reporting of the initial 10 cases. Eur Respir J 2014; 43: 286-289.

Bernard C, Brossier F, Sougakoff W, et al. A surge of MDR and XDR tuberculosis in France among patients born in the Former Soviet Union. Euro Surveill 2013; 18: pii 20555.

Liu Y, Painter JA, Posey DL, et al. Estimating the impact of newly arrived foreign-born persons on tuberculosis in the United States. PLoS One 2012; 7: e32158.

World Health Organization. Systematic screening for active tuberculosis. Principles and recommendations. WHO/HTM/TB/2013.04. Geneva, World Health Organization, 2013.

Kranzer K, Afnan-Holmes H, Tomlin K, et al. The benefits to communities and individuals of screening for active tuberculosis disease: a systematic review. Int J Tuberc Lung Dis 2013; 17: 432-446.

Walter ND, Jasmer RM, Grinsdale J, et al. Reaching the limits of tuberculosis prevention among foreign-born individuals: a tuberculosis-control program perspective. Clin Infect Dis 2008; 46: 103-106.

World Health Organization. Guidelines on the management of latent tuberculosis infection. WHO/HTM/TB/ 2015.01. Geneva, World Health Organization, 2015.

Paquette K, Cheng MP, Kadatz MJ, et al. Chest radiography for active tuberculosis case finding in the homeless: a systematic review and meta-analysis. Int J Tuberc Lung Dis 2014; 18: 1231-1236.

De Vries G, Baars HW, Sebek MM, et al. A transmission classification model to determine place and time of infection of tuberculosis cases in an urban area. J Clin Microbiol 2008; 46: 3924-3930.

Kamper-Jørgensen Z, Andersen AB, Kok-Jensen A, et al. Characteristics of non-clustered tuberculosis in a low burden country. Tuberculosis 2012; 92: 226-231.

Heldal E, Docker H, Caugant DA, et al. Pulmonary tuberculosis in Norwegian patients. The role of reactivation, re-infection and primary infection assessed by previous mass screening data and restriction fragment length polymorphism analysis. Int J Tuberc Lung Dis 2000; 4: 300-307.

Sotgiu G, Bourdin Trunz B, Migliori GB, et al. Childhood tuberculosis outbreaks in EU/EEA: a systematic review. Eur Respir J 2013; 42: Suppl. 57, P1610.

7 Migliori GB, Centis R, D’Ambrosio L, et al. Impact and management of TB childhood outbreaks in EU/EEA. Eur Respir J 2013; 42: Suppl. 57, 3532.

European Centre for Disease Prevention and Control. Investigation and control of tuberculosis incidents affecting children in congregate settings. Stockholm, ECDC, 2013. www.ecdc.europa.eu/en/publications/Publications/ guidance-investigation-control-tb-incidents-children-in-congregate-settings.pdf

Lai RP, Nakiwala JK, Meintjes G, et al. The immunopathogenesis of the HIV tuberculosis immune reconstitution inflammatory syndrome. Eur J Immunol 2013; 43: 1995-2002.

Ferrara G, Murray M, Winthrop K, et al. Risk factors associated with pulmonary tuberculosis: smoking, diabetes and anti-TNF $\alpha$ drugs. Curr Opin Pulm Med 2012; 18: 233-240.

Moore-Gillon J. Diabetes and tuberculosis: a gathering storm? Thorax 2010; 65: 571-572.

Pareek M, Watson JP, Ormerod LP, et al. Screening of immigrants in the UK for imported latent tuberculosis: a multicentre cohort study and cost-effectiveness analysis. Lancet Infect Dis 2011; 11: 435-444. 
133 Cantini F, Niccoli L, Goletti D. Tuberculosis risk in patients treated with non-anti-tumor necrosis factor- $\alpha$ (TNF- $\alpha$ ) targeted biologics and recently licensed TNF- $\alpha$ inhibitors: data from clinical trials and national registries. J Rheumatol Suppl 2014; 91: 56-64.

134 Menzies D, Long R, Trajman A, et al. Adverse events with 4 months of rifampin therapy or 9 months of isoniazid therapy for latent tuberculosis infection: a randomized trial. Ann Intern Med 2008; 149: 689-697.

135 Sterling TR, Villarino ME, Borisov AS, et al. Three months of rifapentine and isoniazid for latent tuberculosis infection. N Engl J Med 2011; 365: 2155-2166.

136 Horsburgh CRJr, Goldberg S, Bethel J, et al. Latent TB infection treatment acceptance and completion in the United States and Canada. Chest 2010; 137: 401-409.

137 Colson PW, Hirsch-Moverman Y, Bethel J, et al. Acceptance of treatment for latent tuberculosis infection: prospective cohort study in the United States and Canada. Int J Tuberc Lung Dis 2013; 17: 473-479.

138 Li J, Munsiff SS, Tarantino T, et al. Adherence to treatment of latent tuberculosis infection in a clinical population in New York City. Int I Infect Dis 2010; 14: e292-e297.

139 Bibi H, Weiler-Ravell D, Shoseyov D, et al. Compliance to treatment of latent tuberculosis infection in a region of Israel. Isr Med Assoc J 2002; 4: 13-16.

140 Goswami ND, Gadkowski LB, Piedrahita C, et al. Predictors of latent tuberculosis treatment initiation and completion at a U.S. public health clinic: a prospective cohort study. BMC Public Health 2012; 12: 468.

141 Trajman A, Long R, Zylberberg D, et al. Factors associated with treatment adherence in a randomised trial of latent tuberculosis infection treatment. Int J Tuberc Lung Dis 2010; 14: 551-559.

142 Kan B, Kalin M, Bruchfeld J. Completing treatment for latent tuberculosis: patient background matters. Int J Tuberc Lung Dis 2013; 17: 597-602.

143 Garie KT, Yassin MA, Cuevas LE. Lack of adherence to isoniazid chemoprophylaxis in children in contact with adults with tuberculosis in Southern Ethiopia. PLoS One 2011; 6: e26452.

144 Cruz AT, Starke JR. Twice-weekly therapy for children with tuberculosis infection or exposure. Int J Tuberc Lung Dis 2013; 17: 169-174.

145 Sarivalasis A, Bodenmann P, Langenskiold E, et al. High rate of completion of preventive therapy for latent tuberculosis infection among asylum seekers in a Swiss Canton. Swiss Med Wkly 2013; 143: w13860.

146 Schaaf HS, Gie RP, Kennedy M, et al. Evaluation of young children in contact with adult multidrug-resistant pulmonary tuberculosis: a 30-month follow-up. Pediatrics 2002; 109: 765-771.

147 Bamrah S, Brostrom R, Dorina F, et al. Treatment for LTBI in contacts of MDR-TB patients, Federated States of Micronesia, 2009-2012. Int J Tuberc Lung Dis 2014; 18: 912-918.

148 World Health Organization. Early detection of tuberculosis: an overview of approaches, guidelines and tools. WHO/HTM/STB/PSI/2011.21. Geneva, World Health Organization, 2011.

149 World Health Organization. Recommendations for investigating the contacts of persons with infectious tuberculosis in low- and middle-income countries. WHO/HTM/TB/2012.9. Geneva, World Health Organization, 2012.

150 Erkens CG, Kamphorst M, Abubakar I, et al. Tuberculosis contact investigation in low prevalence countries: a European consensus. Eur Respir J 2010; 36: 925-949.

151 World Health Organization. WHO policy on TB infection control in health-care facilities, congregate settings and households. WHO/HTM/TB/2009.419. Geneva, World Health Organization, 2009.

152 World Health Organization. Guidelines for the control of tuberculosis in prisons. WHO/TB/98.250. Geneva, World Health Organization, 1998.

153 World Health Organization. Tuberculosis and air travel: guidelines for prevention and control. 3rd Edn. WHO/ HTM/TB/2008.399. Geneva, World Health Organization, 2008.

154 World Health Organization. Tuberculosis care and control in refugee and displaced populations. WHO/HTM/ TB/2007.377. Geneva, World Health Organization, 2007.

155 World Health Organization. Disease outbreaks. http://www.who.int/topics/disease_outbreaks/en/

156 van't Hoog AH, Onozaki I, Lönnroth K. Choosing algorithms for TB screening: a modelling study to compare yield, predictive value and diagnostic burden. BMC Infect Dis 2014; 14: 532.

157 Migliori GB, Sotgiu G, Gandhi NR, et al. Drug resistance beyond extensively drug-resistant tuberculosis: individual patient data meta-analysis. Eur Respir J 2013; 42: 169-179.

158 Fears R, Kaufmann S, Ter Meulen V, et al. Drug-resistant tuberculosis in the European Union: opportunities and challenges for control. Tuberculosis 2010; 90: 182-187.

159 Lange C, Abubakar I, Alffenaar JW, et al. Management of patients with multidrug-resistant/extensively drug-resistant tuberculosis in Europe: a TBNET consensus statement. Eur Respir J 2014; 44: 23-63.

160 World Health Organization. Guidelines for the programmatic management of drug-resistant tuberculosis. Emergency update 2008. WHO/HTM/TB/2008.402. Geneva, World Health Organization, 2008.

161 Carvalho AC, Migliori GB, Cirillo DM. Tuberculosis in Europe: a problem of drug resistance or much more? Expert Rev Respir Med 2010; 4: 189-200.

162 Pontali E, Matteelli A, Migliori GB. Drug-resistant tuberculosis. Curr Opin Pulm Med 2013; 19: 266-272.

163 Ahuja SD, Ashkin D, Avendano M, et al. Multidrug resistant pulmonary tuberculosis treatment regimens and patient outcomes: an individual patient data meta-analysis of 9,153 patients. PLoS Med 2012; 9: e1001300.

164 Jacobson KR, Tierney DB, Jeon CY, et al. Treatment outcomes among patients with extensively drug-resistant tuberculosis: systematic review and meta-analysis. Clin Infect Dis 2010; 51: 6-14.

165 TB CARE I. International Standards for Tuberculosis Care. 3rd Edn. The Hague, TB CARE I, 2014. www.who. int/tb/publications/ISTC_3rdEd.pdf

166 Dheda K, Migliori GB. The global rise of extensively drug-resistant tuberculosis: is the time to bring back sanatoria now overdue? Lancet 2012; 379: 773-775.

167 Laniado-Laborin R, Kiy R, Spanevello A, et al. Declaration on palliative care for MDR/XDR-TB. Int J Tuberc Lung Dis 2012; 16: 1418-1419.

168 Falzon D, Gandhi N, Migliori GB, et al. Resistance to fluoroquinolones and second-line injectable drugs: impact on multidrug-resistant TB outcomes. Eur Respir J 2013; 42: 156-168.

169 Skripconoka V, Danilovits M, Pehme L, et al. Delamanid improves outcomes and reduces mortality in multidrug-resistant tuberculosis. Eur Respir J 2013; 41: 1393-1400. 
Gler MT, Skripconoka V, Sanchez-Garavito E, et al. Delamanid for multidrug-resistant pulmonary tuberculosis. N Engl J Med 2012; 366: 2151-2160.

Diacon AH, Dawson R, von Groote-Bidlingmaier F, et al. 14-day bactericidal activity of PA-824, bedaquiline, pyrazinamide, and moxifloxacin combinations: a randomised trial. Lancet 2012; 380: 986-993.

Tiberi S, De Lorenzo S, Centis R, et al. Bedaquiline in MDR/XDR-TB cases: first experience on compassionate use. Eur Respir J 2014; 43: 289-292.

Zumla A, Nahid P, Cole ST. Advances in the development of new tuberculosis drugs and treatment regimens. Nat Rev Drug Discov 2013; 12: 388-404.

World Health Organization. Introduction and rational use of new drugs/regimens for the treatment of tuberculosis in countries. Date last accessed: October 23, 2014.

European Centre for Disease Prevention and Control, WHO Regional Office for Europe. Tuberculosis surveillance and monitoring in Europe 2013. Stockholm, ECDC, 2013.

World Health Organization. Understanding and using tuberculosis data. WHO/HTM/TB/2014.09. Geneva, World Health Organization, 2014.

Nunes C. Tuberculosis incidence in Portugal: spatiotemporal clustering. Int J Health Geogr 2007; 6: 30.

Moonan PK, Ghosh S, Oeltmann JE, et al. Using genotyping and geospatial scanning to estimate recent Mycobacterium tuberculosis transmission, United States. Emerg Infect Dis 2012; 18: 458-465.

Jia ZW, Jia XW, Liu YX, et al. Spatial analysis of tuberculosis cases in migrants and permanent residents, Beijing, 2000-2006. Emerg Infect Dis 2008; 14: 1413-1419.

World Health Organization. A practical handbook on the pharmacovigilance of medicines used in the treatment of tuberculosis: enhancing the safety of the TB patient. Geneva, World Health Organization, 2012.

Frick M, Jiménez-Levi E. 2013 Report on Tuberculosis Research Funding Trends, 2005-2012. New York, Treatment Action Group, 2013.

Migliori GB, Sotgiu G. Treatment of tuberculosis: have we turned the corner? Lancet 2012; 380: 955-957.

Migliori GB, Lienhardt C, Weyer K, et al. Ensuring rational introduction and responsible use of new TB tools: outcome of an ERS multisector consultation. Eur Respir J 2014; 44: 1412-1417.

Evans TG, Brennan MJ, Barker L, et al. Preventive vaccines for tuberculosis. Vaccine 2013; 31: Suppl. 2, B223-B226.

Dara M, Acosta CD, Rusovich V, et al. Bacille Calmette-Guerin vaccination: the current situation in Europe. Eur Respir J 2014; 43: 24-35. 